\title{
Microsurgical anatomy and internal architecture of the brainstem in 3D images: surgical considerations
}

\author{
Richard Gonzalo Párraga, MD,-3 Lucas Loss Possatti, MD,1,2 Raphael Vicente Alves, MD, PhD, 1,2 \\ Guilherme Carvalhal Ribas, MD, PhD, ${ }^{4}$ Uğur Türe, MD, ${ }^{5}$ and Evandro de Oliveira, MD, PhD1,2,6 \\ ${ }^{1}$ Institute of Neurological Sciences (ICNE), São Paulo; ${ }^{2}$ Microneurosurgery Laboratory, Beneficência Portuguesa Hospital, \\ São Paulo; ${ }^{4}$ Department of Surgery-LIM 02, University of São Paulo Medical School (FMUSP), São Paulo; ${ }^{6}$ Department of \\ Neurosurgery, State University of Campinas (UNICAMP), Campinas, São Paulo, Brazil; ${ }^{3}$ Department of Neurological Surgery, \\ Hospital UNIVALLE, Cochabamba-Cercado, Bolivia; and ${ }^{5}$ Department of Neurosurgery, Yeditepe University School of Medicine, \\ Istanbul, Turkey
}

\begin{abstract}
OBJECTIVE Brainstem surgery remains a challenge for the neurosurgeon despite recent improvements in neuroimaging, microsurgical techniques, and electrophysiological monitoring. A detailed knowledge of the microsurgical anatomy of the brainstem surface and its internal architecture is mandatory to plan appropriate approaches to the brainstem, to choose the safest point of entry, and to avoid potential surgical complications.
\end{abstract}

METHODS An extensive review of the literature was performed regarding the brainstem surgical approaches, and their correlations with the pertinent anatomy were studied and illustrated through dissection of human brainstems properly fixed with $10 \%$ formalin. The specimens were dissected using the fiber dissection technique, under $\times 6$ to $\times 40$ magnification. 3D stereoscopic photographs were obtained (anaglyphic 3D) for better illustration of this study.

RESULTS The main surgical landmarks and their relationship with the cerebellum and vascular structures were identified on the surface of the brainstem. The arrangements of the white matter (ascending and descending pathways as well as the cerebellar peduncles) were demonstrated on each part of the brainstem (midbrain, pons, and medulla oblongata), with emphasis on their relationships with the surface. The gray matter, constituted mainly by nuclei of the cranial nerves, was also studied and illustrated.

CONCLUSIONS The objective of this article is to review the microsurgical anatomy and the surgical approaches pertinent to the brainstem, providing a framework of its external and internal architecture to guide the neurosurgeon during its related surgical procedures.

http://thejns.org/doi/abs/10.3171/2015.4.JNS132778

KEY WORDS brainstem; fiber dissection; microsurgical anatomy; safe entry zone; surgical approaches; posterior fossa

$\mathrm{T}$ HE brainstem forms the central axis of the brain and comprises the midbrain, pons, and medulla oblongata; it occupies the anterior portion of the cranial posterior fossa (Fig. 1). It is composed of neurons aggregated into nuclei and nerve fibers grouped into bundles called tracts, fasciculi, or lemnisci. These elements of the internal structure may be related to prominences or depressions on the surface, which must be identified by the surgeon. The brainstem is basically composed of 4 types of structures: 1) ascending and descending pathways that connect the spinal cord with the prosencephalon; 2) reflex centers associated with control of breathing, the cardiovascular system, and also consciousness, along the reticu- lar formation; 3 ) most of the nuclei of the cranial nerves (from CN III to XII); and 4) cerebellar peduncles. ${ }^{23,36,41,43,49}$

Brainstem surgery remains a challenge for the neurosurgeon. Recent improvements in neuroimaging, microsurgical techniques, and electrophysiological monitoring, in association with detailed knowledge of regional and functional anatomy, have allowed surgical procedures at this region to become safer and more likely to be successful. To plan the most appropriate approaches, to choose the safest entry zones, and to minimize possible surgical complications, ${ }^{14,41}$ it is important for the neurosurgeon to keep in mind both the surface anatomy and the internal architecture of the brainstem. 


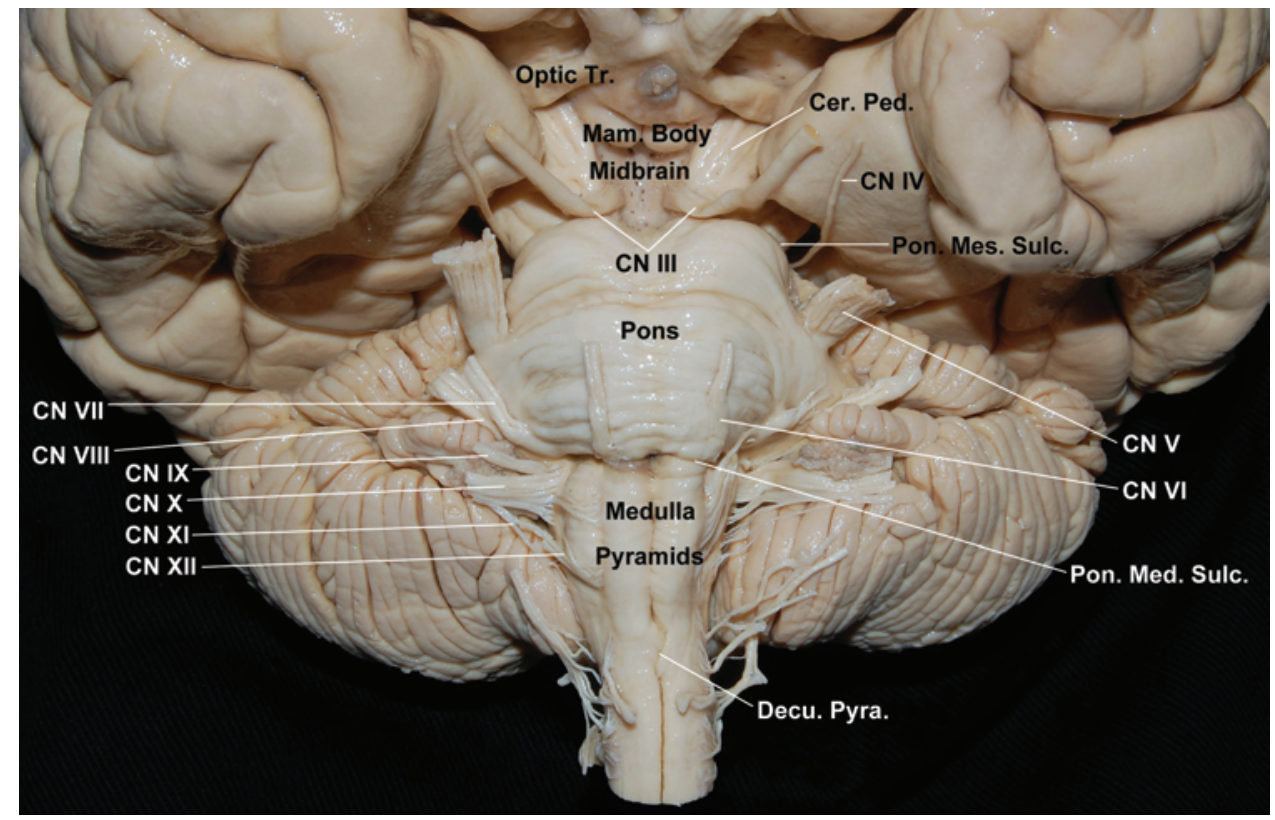

FIG. 1. Anterior view of the brainstem. Cer. Ped. = cerebral peduncles; Decu. Pyra = decussation of the pyramids; Mam. Body = mammillary body; Optic Tr. = optic tract; Pon. Med. Sulc. = pontomedullary sulcus; Pon. Mes. Sulc. = pontomesencephalic sulcus. Figure is available in color online only.

\section{Methods}

This study is based on an extensive bibliographic review of the main surgical approaches to the brainstem, describes the external and the internal microsurgical anatomy of the brainstem, and is illustrated with stereoscopic $3 \mathrm{D}$ images ${ }^{11,32,38}$ of magnified dissections of 5 human anatomical specimens prepared using Klingler's freezing method and submitted to the fiber dissection technique. ${ }^{11,19,21,38,50}$ The bibliographic review was performed by searching for the key words in PubMed and reference textbooks. The dissections were done with microsurgical techniques and with magnification $(\times 6$ to $\times 40)$ provided by an M900 D.F. Vasconcellos microscope (D.F. Vasconcellos S.A.).

Stereoscopic images were obtained using a Nikon D40 camera and the following lenses: AF-S Nikkor $18-55 \mathrm{~mm}$ 1:3.5-5.6 GII ED and AF-S VR Micro-Nikkor $105 \mathrm{~mm}$ $\mathrm{f} / 2.8 \mathrm{G}$ (Nikon Corp.). The callipygian software was used for the development of the anaglyphic images (Callipyan 3D, Copyright 2003, Robert Swirsky).

\section{Results}

\section{Midbrain}

The midbrain is the cranial part of the brainstem, situated between the pons and the diencephalon. The midbrain is separated from the diencephalon by an imaginary plane that links the mammillary bodies to the posterior commissure. ${ }^{22,23,36,43,44,49,51,52}$

\section{External Morphology and Relationships}

The superior limit of the midbrain is the optic tract, and the inferior limit is the pontomesencephalic sulcus, which extends from the superior foramen cecum and courses around the cerebral peduncles to reach the lateral mesencephalic sulcus. ${ }^{22,23,36,43,49,51}$ The 2 cerebral peduncles have diverge to create an $80^{\circ}$ angular space called the interpeduncular fossa, a triangular depression with the apex oriented inferiorly and formed by the superior foramen cecum and a superior base represented by the mammillary bodies. The interpeduncular fossa harbors the posterior perforated substance and is limited laterally by the oculomotor nerves and the base of the cerebral peduncles. The midbrain occupies the largest part of the incisural space, ${ }^{31}$ also known as the foramen of Pacchioni, ${ }^{49}$ and has a height of 15-18 mm, a width of 12-14 $\mathrm{mm}$ at its caudal part and $18-20 \mathrm{~mm}$ at its cranial part, and an anteroposterior diameter of 20-22 mm.49

Anterior Surface. The midbrain is visible on the base of the encephalon after removing the uncus of the temporal lobe. The emergence of the third cranial nerve is visualized at the medial sulcus of the cerebral peduncle. In some specimens, the longitudinal fasciculi of the cerebral peduncles are crossed by transverse fibers, which extend from the dorsal and external aspect of the cerebral peduncle to the interpeduncular fossa. There are 3 formations: 1) Féré's band fasciculus, constituted by aberrant fibers of the pyramidal pathway that unite with the medial lemniscus; 2) tenia pontis, formed by pons fibers that enter the oculomotor sulcus; and 3) tractus peduncularis transversus, fibers born from the superior colliculus and part of the inferior colliculus that course toward the oculomotor sulcus (Fig. 1). ${ }^{49}$

Posterior Surface. There are 4 round eminences of the midbrain called the superior and inferior colliculi, which are also known as the quadrigeminal tubercles.

Lateral Surface. The lateral surface is hidden by the uncus and parahippocampal gyrus, and is divided into 2 
parts by a longitudinal sulcus called the lateral mesencephalic sulcus, which extends from the pontomesencephalic sulcus to the medial geniculate body. The anterior part is continuous with the cerebral peduncles and the posterior part has a triangular shape, limited by the lateral mesencephalic sulcus anteriorly, the posterior conjunctival brachium superiorly, and the superior cerebellar peduncle inferiorly. This space is termed the lemniscal trigone (Reil's trigone ${ }^{49}$ ), and it is occupied by the acoustic fasciculus (Fig. 2). ${ }^{29,43,49}$

Superior and Inferior Extremities. One part of the superior extremity is continuous with the subthalamic region and the other with the internal capsule. The inferior extremity is continuous with the pons (protuberance).

\section{Internal Morphology}

The midbrain is divided by an imaginary line that crosses the cerebral aqueduct (sylvian aqueduct ${ }^{49}$ ) and consists of a posterior part termed the tectum and an anterior part called the cerebral peduncles. Each peduncle is subdivided by the substantia nigra into 2 parts: an anterior part (crus cerebri) and a posterior part (tegmentum). ${ }^{22,49,55}$

Crus Cerebri. The crus cerebri corresponds to the continuation of the internal capsule below each thalamus, has the aspect of a half-moon, and is composed of 3 parts: 1) the internal segment, which represents one-fifth of the crus cerebri and is formed by the frontopontine fibers (Arnold's fasciculus ${ }^{49}$ ) and by the corticonuclear fibers (geniculate fasciculus ${ }^{49}$ ) that originate from the inferior portion of the precentral gyrus; 2) the intermediate segment, which contains the second, third, and fourth parts of the crus and is formed by fibers of the pyramidal pathway that originate in the cortex of the precentral gyrus; and 3) the external segment, which occupies the external one-fifth of the crus, is formed by temporopontine fibers (Türk's fasciculus ${ }^{49}$ ), in addition to fibers that originate from the parietal and occipital cortex, and ends at the nuclei of the pons..$^{30,43,49,55}$
Tegmentum. The tegmentum is square and is limited by the substantia nigra anteriorly and by an arbitrary transverse plane through the aqueduct posteriorly. Externally it is limited by the lateral aspect of the midbrain and internally by the median raphe. The tegmentum is formed by the following. ${ }^{29,49}$

Reticular Formation. The reticular formation is composed of a group of neurons and nerve fibers disposed as a net throughout the brainstem. It has an irregular structure, but some groups of neurons can be defined; these constitute the nuclei of the reticular formation, in particular the raphe nuclei, locus coeruleus, periaqueductal gray matter, and ventral tegmental area. In the midbrain, the reticular formation begins under the thalamus in front of the quadrigeminal tubercles and occupies a triangular area between the red nucleus anteriorly, the central gray matter medially, and the posterior commissure posteriorly.

The fibers that course through the reticular formation follow the course of an arc and include the tectobulbar fibers, the tegmen radiation, the rubrospinal fasciculus, the superior cerebellar peduncles, and the medial longitudinal fasciculus and medial lemniscus. The tectobulbar fibers course from the superior colliculus to the medulla oblongata. These fibers create an intersection on the midline called the dorsal tegmental decussation (decussation of Meynert $\left.{ }^{49}\right)$. The tegmen radiation is composed of rubrothalamic fibers. The rubrospinal fasciculus constitutes the ventral tegmental decussation (Forel's decussation ${ }^{49}$ ).

Gray Matter. The gray matter of the midbrain can be categorized as gray matter homologous to spinal cord (nuclei of cranial nerves) and the midbrain's own gray matter (red nucleus and substantia nigra).

The nuclei of the cranial nerves that constitute the homologous gray matter are the trochlear nucleus, the oculomotor nucleus, and the mesencephalic tract nucleus of the trigeminal nerve.
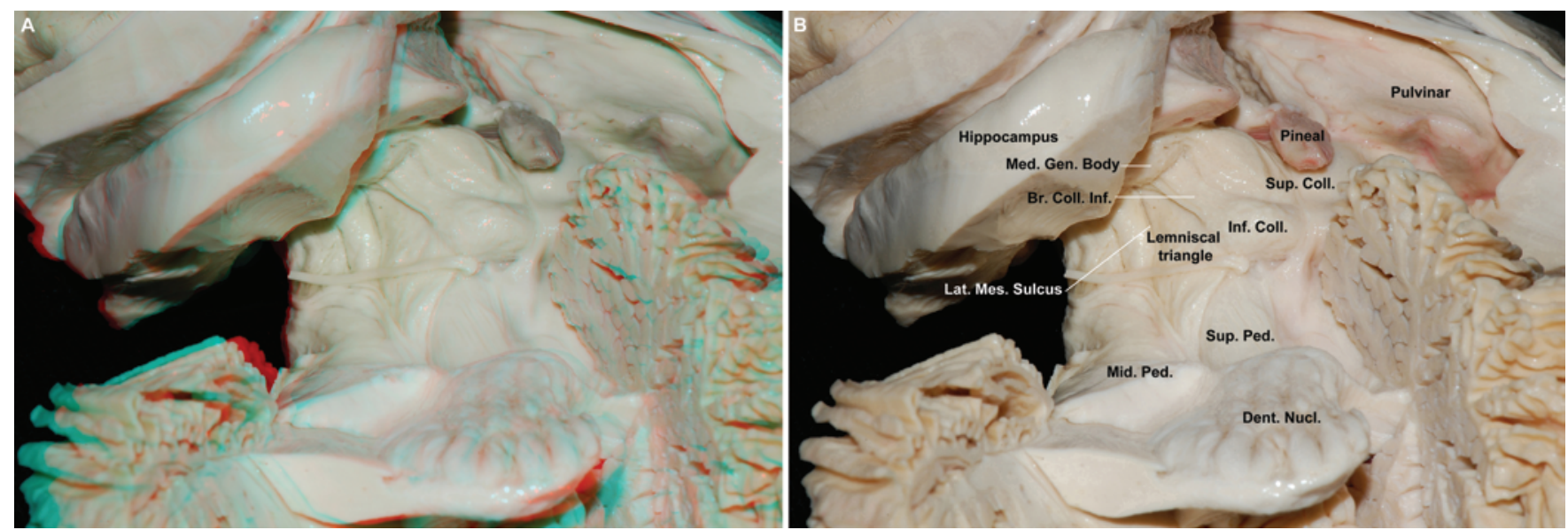

FIG. 2. 3D (A) and 2D (B) images. Lateral view of the midbrain. The left cerebellar hemisphere and vermis were partially removed. The dentate nucleus (Dent. Nucl.) was preserved with the dentorubral pathway in the superior cerebellar peduncle (Sup. Ped). The lemniscal trigone or Reil's trigone, which is limited by the lateral mesencephalic sulcus (Lat. Mes. Sulcus) anteriorly, the posterior conjunctival brachium superiorly, and the superior cerebellar peduncle inferiorly, is demonstrated. Br. Coll. Inf. = brachium of the inferior colliculus; Inf. Coll. = inferior colliculus; Med. Gen. Body = medial geniculate body; Mid. Ped. = middle cerebellar peduncle; Sup. Coll. = superior colliculus. Figure is available in color online only. 
The trochlear nucleus is situated in the ventral region of the periaqueductal gray matter at the level of the inferior colliculus. The axons surround the aqueduct end emerging from the sides of the frenulum of the superior medullary velum (bridle of valve of Vieussens ${ }^{49}$ ) (Figs. 3 and 4) and innervate the superior oblique muscle in the ocular globe.

The oculomotor nucleus forms a column at the level of the superior colliculus, between the periaqueductal gray matter and the medial longitudinal fasciculus, upward to the posterior commissure. It contains 3 nuclei: the oculomotor nucleus that innervates the ipsilateral superior, medial, and inferior rectus muscles, in addition to the inferior oblique and levator palpebrae muscles; Perlia's nucleus, responsible for mobility of the ocular globe convergence; and the accessory oculomotor (Edinger-Westphal's) nucleus, a parasympathetic nucleus that controls the sphincter and the ciliary muscles responsible for the accommodation reflex (Fig. 5). Damage to the oculomotor nucleus causes ipsilateral paresis of eye movements. ${ }^{14,29,43,49}$

The mesencephalic tract nucleus of the trigeminal nerve continues from the pons.

The gray matter of the midbrain's consists of the red nucleus, the substantia nigra, the inferior colliculus nucleus, the superior colliculus, and the pretectal area.

The red nucleus (Stilling's ${ }^{49}$ ) is an oval structure, extending 6-7 $\mathrm{mm}$ from the subthalamic region to the inferior one-third of the peduncle. At the junction of the anterior one-third with the posterior two-thirds the nucleus is narrowed by the habenulo-interpeduncular tract (Meynert's retroreflex fasciculus), a tract that connects the habenular nuclei with the interpeduncular ganglion. ${ }^{21,30,49}$ Its dorsal surface, from inside to outside, harbors the oculomotor nucleus, the medial longitudinal fasciculus, and the reticular formation (Fig. 5). The afferent fibers connected to the red nucleus are the cerebellorubral pathway, the estriatorubral pathway, and the corticorubral pathway. The dentatorubrothalamic system is formed by the supe- rior cerebellar peduncle. This pathway arises from the dentate nucleus and decussates at the pontomesencephalic joint (decussation of Wernekinck ${ }^{49}$ ) to reach the contralateral red nucleus. The striatorubral pathway arises from the lentiform nucleus and gives rise to part of Forel's fasciculus and the ansa lenticularis. The corticorubral pathway consists of fibers from the frontal and temporal lobes.

The efferent fibers connected to the red nucleus are the rubrothalamic fasciculus, the rubrospinal fasciculus, and the rubro-olivary pathway. The rubrothalamic fasciculus arises from the capsule and anterior pole of the red nucleus, and ends at the external part of the thalamus. The rubrospinal fasciculus intersects with the contralateral rubrospinal fasciculus on the midline to give rise to the ventral tegmental decussation (of Forel $^{49}$ ) and ends at neurons of the anterior horn of the spinal cord. The rubro-olivary pathway is a central fasciculus in the tegmen, which begins at the thalamus, receives fibers from the red nucleus, and ends at the medullary olive. The red nucleus is linked to the subthalamic region, with Luys' body and nucleus of the zona incerta (Fig. 5). ${ }^{49}$ It is an extrapyramidal motor nucleus that participates in the control of muscle tonus, and damage to it results in contralateral ataxia and tremor. ${ }^{14,29,30,49}$

The substantia nigra (Soemmering's locus niger ${ }^{49}$ ) extends from the lateral mesencephalic sulcus to the oculomotor sulcus lateromedially, and from the highest part of the pons to the subthalamic nucleus (Luys's body ${ }^{49}$ ) craniocaudally (Fig. 6). ${ }^{14,29,30,49}$ The nerve cells of the substantia nigra use dopamine and GABA as neurotransmitters and are involved in muscular tonus control; they have connections with the cortex, spinal cord, hypothalamus, and basal nuclei. Injury to the substantia nigra may lead to parkinsonism. ${ }^{7}$ The tectum is made up of the superior colliculi (associated with the visual pathways) and the inferior colliculi (associated with the auditory pathways), known together as the quadrigeminal plate..$^{14,22,43,49}$ The pretectal area is superiorly located at the midbrain tectum
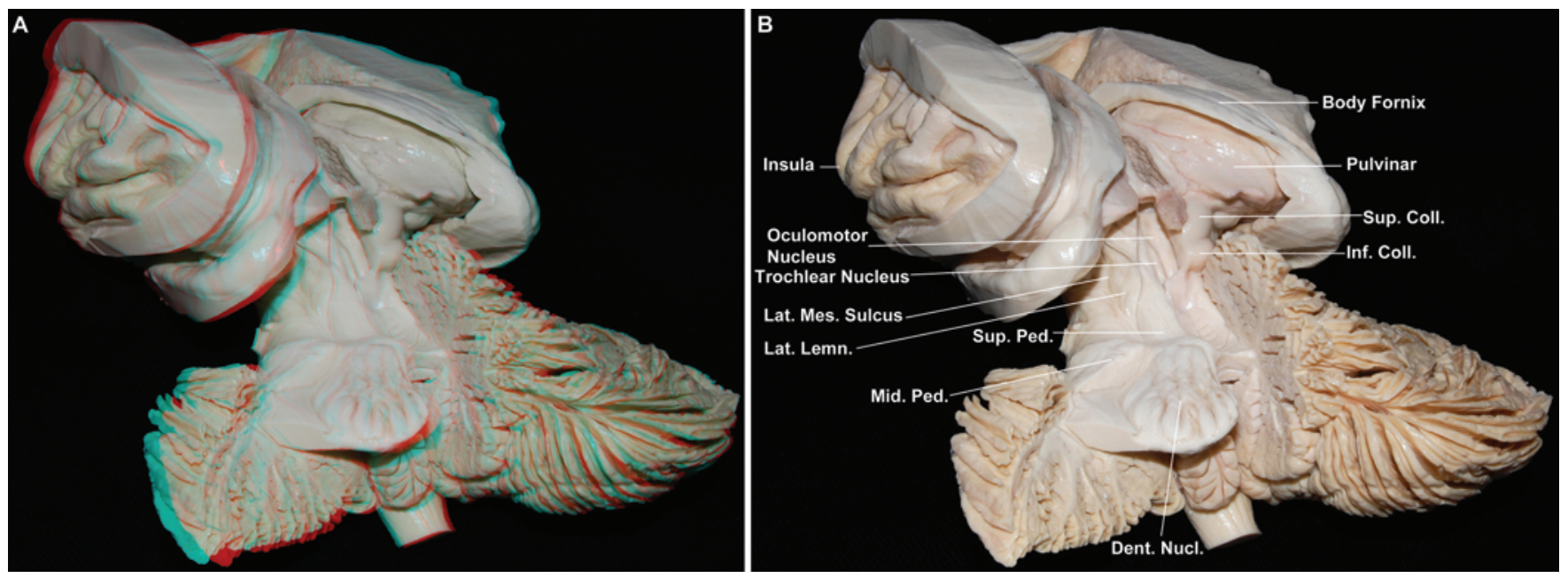

FIG. 3. 3D (A) and 2D (B) images. Posterolateral view of the brainstem and of the central core of the brain. The left superior and inferior colliculi and the cerebral aqueduct were removed to allow identification of CNs III and IV and of the medial longitudinal fasciculus. The left cerebellar hemisphere was also removed, preserving the dentate nucleus (Dent. Nucl.). Inf. Coll. = inferior colliculus; Lat. Lemn. = lateral lemniscus; Lat. Mes. Sulcus = lateral mesial sulcus; Mid. Ped. = middle cerebellar peduncle; Sup. Coll. $=$ superior colliculus; Sup. Ped. = superior cerebellar peduncle. Figure is available in color online only. 

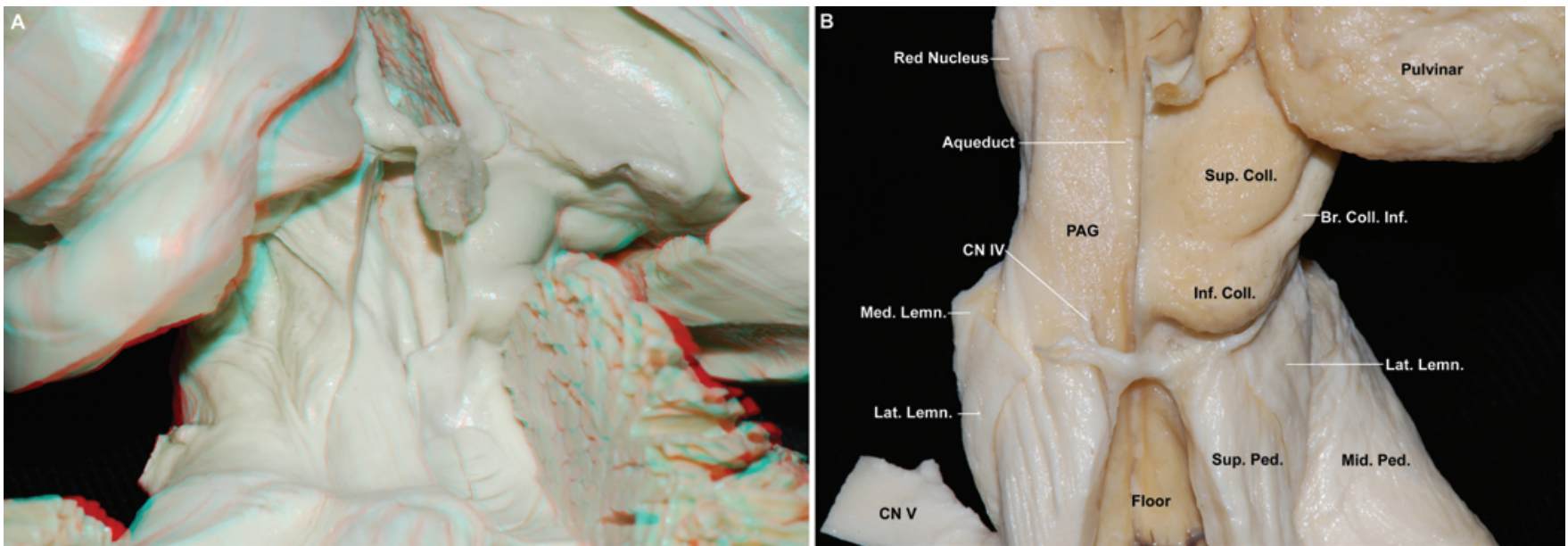

FIG. 4. A: 3D image, magnified view of the specimen shown in Fig. 3. B: Posterior surface of the midbrain. The left superior and inferior colliculi were removed, exposing the cerebral aqueduct and the course of CN IV on the periaqueductal gray matter. $\mathrm{Br}$. Coll. Inf. = brachium of the inferior colliculus; Inf. Coll. = inferior colliculus; Med. Lemn. = medial lemniscus; PAG = periaqueductal gray matter; Mid. Ped. = middle cerebellar peduncle; Sup. Coll. = superior colliculus; Sup. Ped. = superior cerebellar peduncle. Figure is available in color online only.

(rostral to the superior colliculi), and it is associated with reflex control of the pupils. ${ }^{22}$

White Matter. The fibers located in the midbrain can be grouped into longitudinal and transverse fibers. The transverse fibers include the inferior colliculus commissure and the decussation of the superior cerebellar peduncle. The longitudinal fibers include descending, ascending, and association fibers. The descending fibers are the corticospinal tract, the corticonuclear tract, the corticopontine tract, the tectospinal tract, and the rubrospinal tract.

The ascending fibers include the superior cerebellar peduncles, the medial lemniscus, the lateral lemniscus, the spinal lemniscus, and the trigeminal lemniscus.
The superior cerebellar peduncles contain efferent fibers from the dentate nucleus of the cerebellum to the opposite red nucleus (the dentatorubrothalamic system) and the ventral spinocerebellar tracts. The cerebellar fibers decussate just below the red nuclei (decussation of Wernekinck) to give rise to the white nucleus of Stilling ${ }^{49}$ (Figs. 7-9).

The medial lemniscus (medial band of Reil ${ }^{49}$ ) runs along the brainstem at the limit between the crus and the tegmentum. It appears in the medulla oblongata as fibers of the gracile nucleus (Goll's ${ }^{49}$ ) and cuneate nucleus (Burdach's $\left.{ }^{49}\right)$, which intersect on the midline originating the (piniforme decussation ${ }^{49}$ ). After that, the medial lemniscus runs on the posterior face of the pyramidal fasciculus
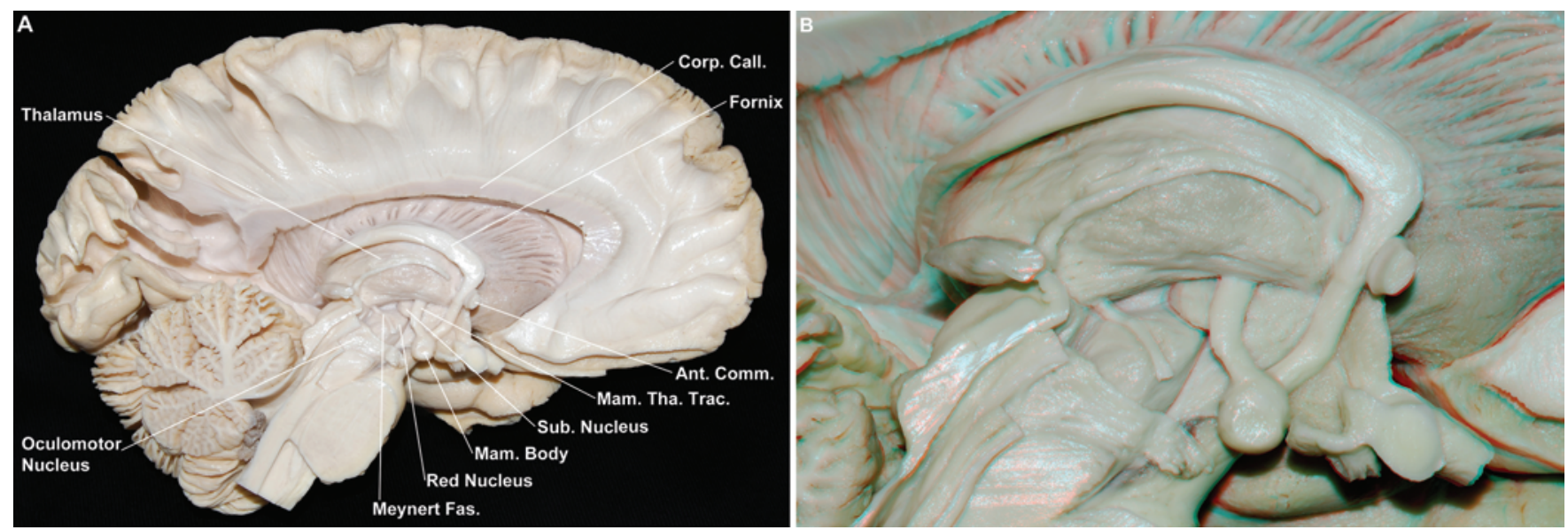

FIG. 5. A: Medial surface of the left hemisphere and brainstem. Identification of the cerebral peduncle gray matter nuclei: red nucleus, with oval shape, extending from the subthalamic region to the inferior third of the peduncle. At the union of the anterior one-third with the posterior two-thirds this nucleus is narrowed by the Meynert's retroreflexus fasciculus (Meynert Fas.). On the dorsal surface, from inside to outside: oculomotor nucleus, medial longitudinal fasciculus, and reticular formation. Ant. Comm. = anterior commissure; Corp. Call. = corpus callosum; Mam. Body = mammillary body; Mam. Tha. Trac. = mammillothalamic tract; Sub. Nucleus = subthalamic nucleus. B: 3D image. Magnified view from the same specimen. Figure is available in color online only. 

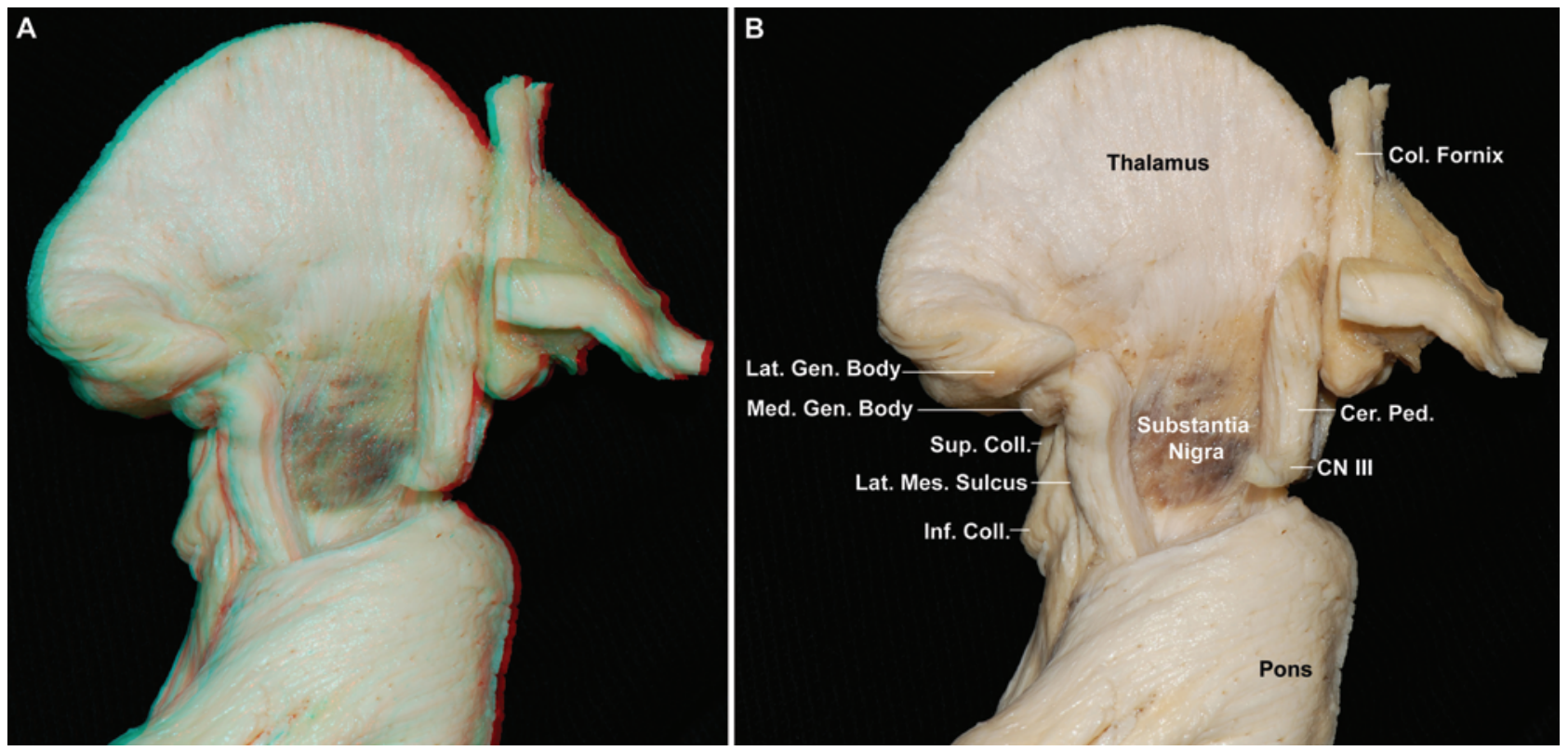

FIG. 6. 3D (A) and 2D (B) images. Anterolateral view of the thalamus and midbrain. The internal capsule and the crus cerebri were partially removed to expose the substantia nigra. Cer. Ped. = cerebral peduncles; Col. Fornix = columns of the fornix; Inf. Coll. = inferior colliculus; Lat. Gen. Body = lateral geniculate body; Lat. Mes. Sulcus = lateral mesencephalic sulcus; Med. Gen. Body = medial geniculate body; Sup. Coll. = superior colliculus. Figure is available in color online only.

and is located at the pons behind the transverse fibers. At the midbrain, it is situated behind the substantia nigra, and it courses externally toward the medial geniculate body. The medial lemniscus ends at the ventral posterolateral nucleus of the thalamus (Fig. 8), projecting through the posterior arm of the internal capsule to Brodmann areas 3, 1, and 2.43,49 The medial lemniscus carries conscious epicritic touch, touch-pressure sense, direction and amplitude of movements, vibration, and postural sensations. Its injury causes contralateral hemianesthesia of the trunk and extremities. $^{14}$
The lateral lemniscus (lateral band of Reil ${ }^{49}$ ) appears at the pons above the trapezoid body, where it joins the medial lemniscus and gives rise to a prominence on the external aspect of the peduncle, called the lateral fasciculus of the isthmus, and ends at the inferior colliculus. It corresponds to the central acoustic pathway (Fig. 9).

The spinal lemniscus is formed by the union of the anterior and lateral spinothalamic tracts, and the trigeminal lemniscus connects the sensory nuclei of the trigeminal nerve to the ventral posteromedial nucleus of the thalamus.
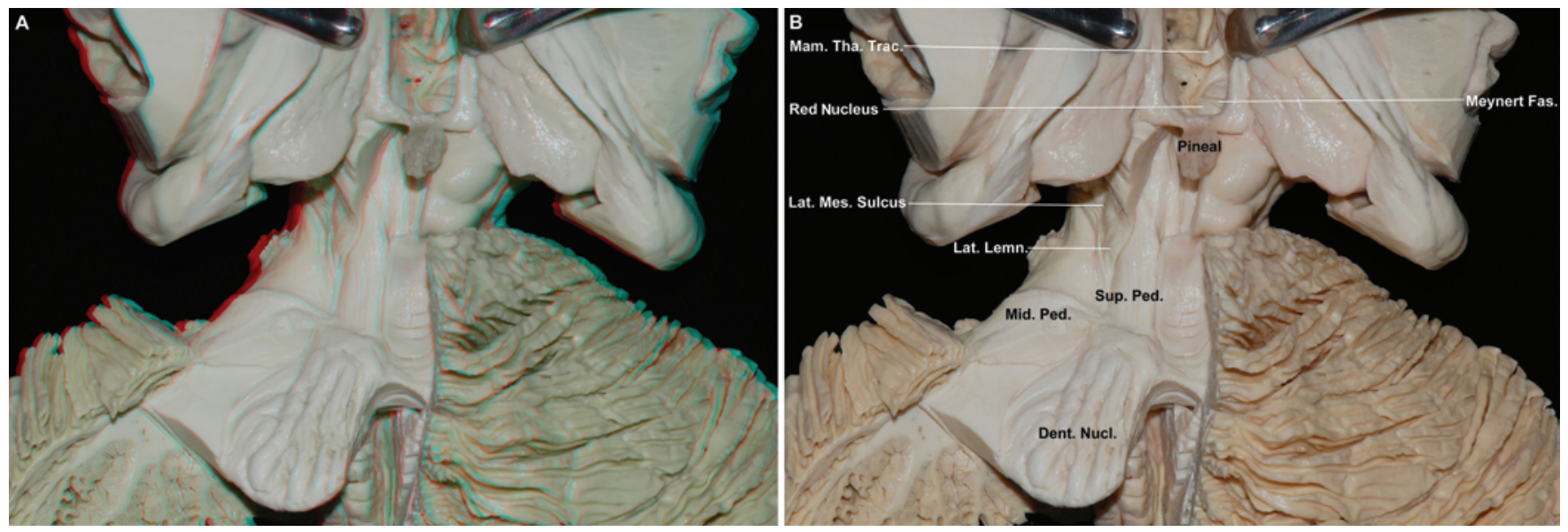

FIG. 7. 3D (A) and 2D (B) images. Posterior view of the midbrain and tentorial surface of the right cerebellar hemisphere. Identification of the rubrocerebellar pathway, which forms the superior cerebellar peduncle (Sup. Ped.), arises from the dentate nucleus (Dent. Nucl.), and crosses toward the contralateral red nucleus at the tegmen of the midbrain. Lat. Lemn. = lateral lemniscus; Lat. Mes. Sulcus = lateral mesencephalic sulcus; Mam. Tha. Trac. = mamillothalamic tract. Meynert Fas. = Meynert fasciculus; Mid. Ped. $=$ middle cerebellar peduncle. Figure is available in color online only. 

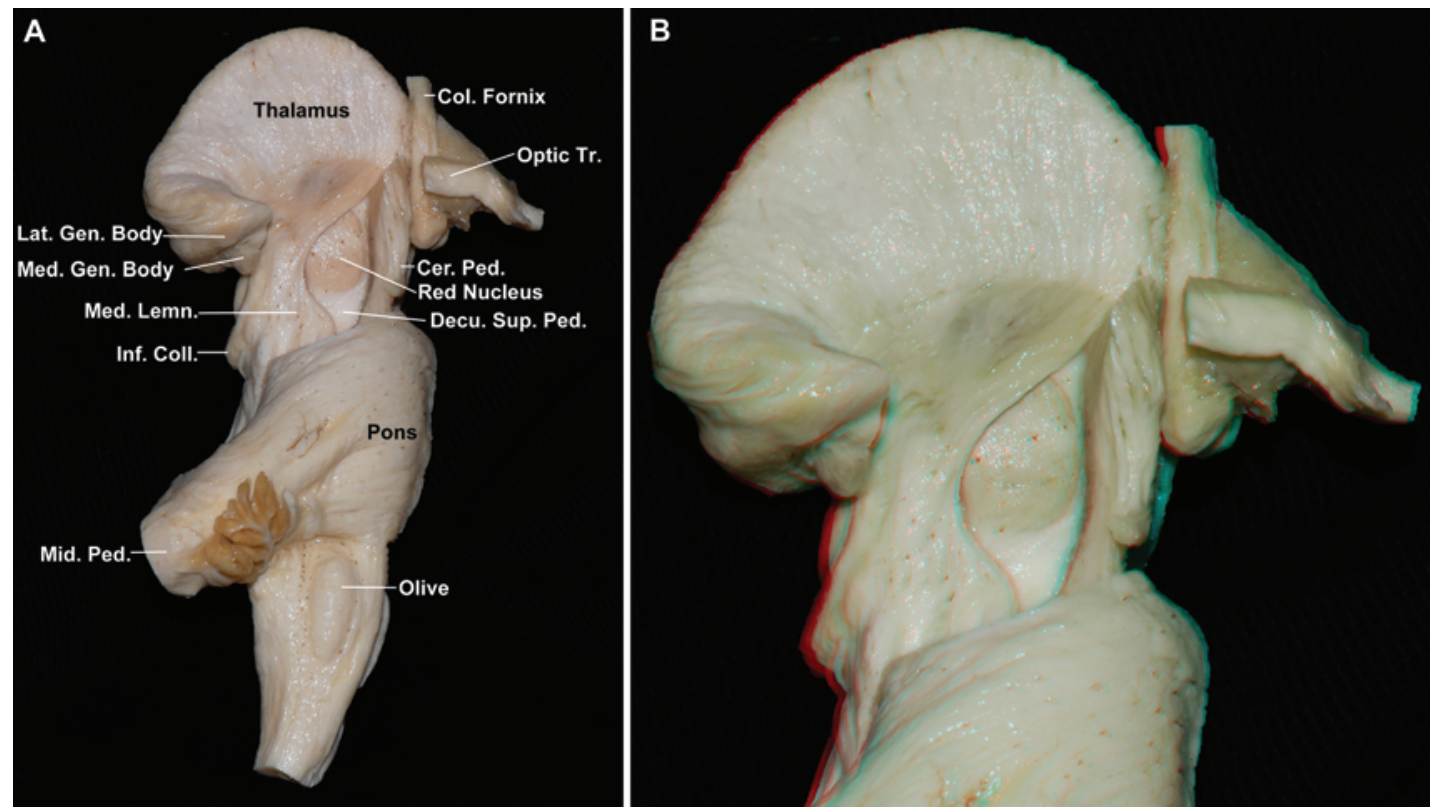

FIG. 8. A: Anterolateral view of the brainstem. The lateral mesencephalic sulcus was opened and enlarged to remove the crus cerebri and the substantia nigra. The course of the medial lemniscus (Med. Lemn.) until the thalamus is shown with its relationship with the red nucleus. Cer. Ped. = cerebral peduncles; Col. Fornix = columns of the fornix; Decu. Sup. Ped. = decussation of the superior cerebellar peduncle; Inf. Coll. = inferior colliculus; Lat. Gen. Body = lateral geniculate body; Med. Gen. Body = medial geniculate body; Mid. Ped. = middle cerebellar peduncle; Optic Tr. = optic tract. B: Image in 3D. Magnified view of the same specimen, at the level of thalamus and midbrain. Figure is available in color online only.

The longitudinal association fiber corresponds to the medial longitudinal fasciculus, which is located at the level of the midbrain, close to the midline and anterior to the oculomotor nuclei. The medial longitudinal fasciculus extends through the brainstem and connects all nuclei of the cranial nerves, especially the nerves related to head and eyeball movements.

Quadrigeminal Tubercles. The quadrigeminal tubercles are prominences on either side of the midline, superior to the superior medullary velum. There are 2 superior
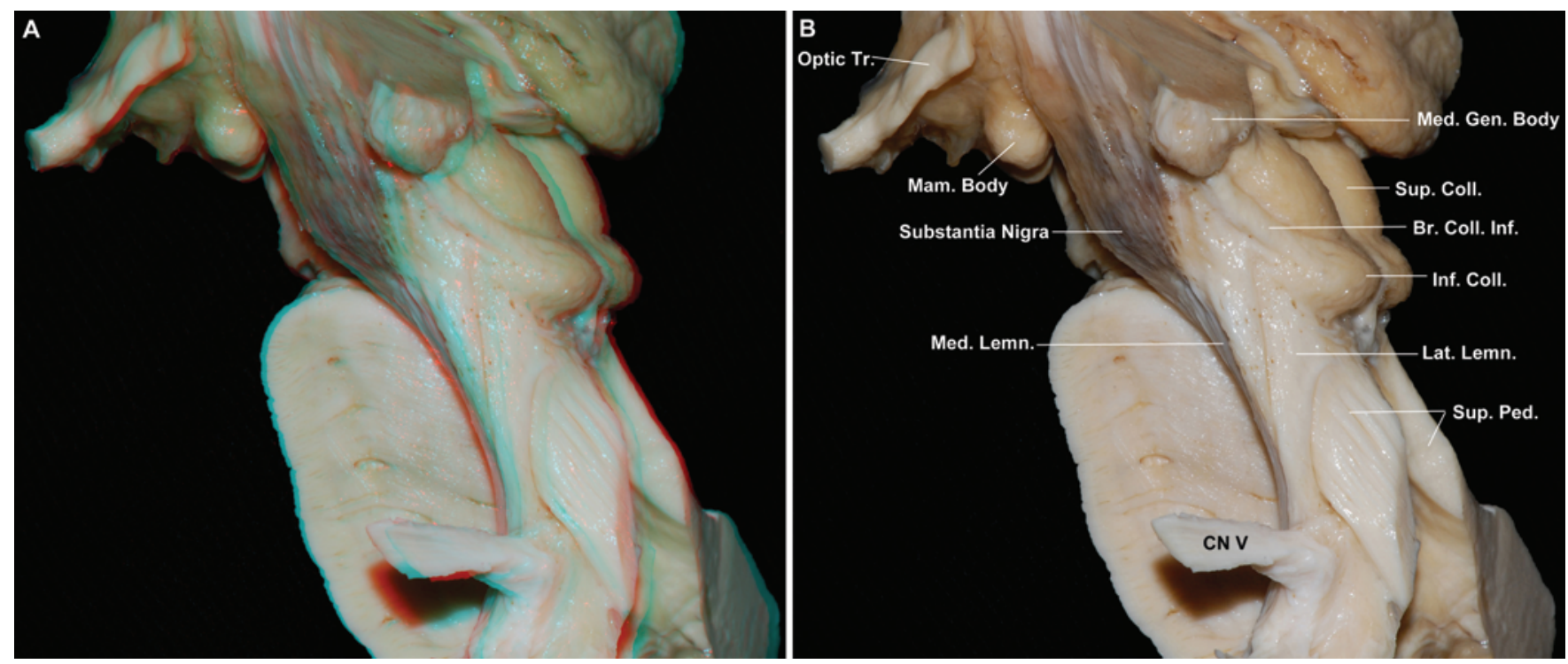

FIG. 9. 3D (A) and 2D (B) images. Lateral view of the midbrain and pons. The base of the cerebral crus and part of the pons with the left middle cerebellar peduncle were removed to identify the course of the medial lemniscus (Med. Lemn.) and also the lateral lemniscus (Lat. Lemn.), which ends at the inferior colicullus (Inf. Coll.). Br. Coll. Inf. = brachium of the inferior colliculus; Mam. Body $=$ mammillary body; Med. Gen. Body = medial geniculate body; Optic Tr. = optic tract; Sup. Coll. = superior colliculus; Sup. Ped. = superior cerebellar peduncle. Figure is available in color online only. 
and 2 inferior colliculi, separated by the cruciform sulcus, and the subpineal triangle (triangle of Obersteiner ${ }^{49}$ ), where the pineal gland rests, is located between the upper ones. The anterior conjunctival arm connects the superior colliculus with the lateral geniculate body, is related with the visual pathway, and participates in reflex movements of the vertical gaze. The posterior conjunctival arm connects the inferior colliculus with the medial geniculate body as part of the acoustic pathway. Damage to the superior colliculi causes pupillary dysfunction and palsy of the vertical gaze. Damage to the inferior colliculi causes hearing loss and makes it impossible to localize sounds in space. ${ }^{13,14,58}$

\section{Pons}

The pons is also termed Varolio's pons ${ }^{49}$ and consists of the portion of the brainstem situated between the midbrain and the medulla oblongata (Fig. 1).

\section{External Morphology}

The pons is cubic in shape and has an average height of $27 \mathrm{~mm}$, width of $38 \mathrm{~mm}$, and anteroposterior diameter of $25 \mathrm{~mm} .{ }^{49}$ Its anterior surface is limited superiorly by the pontomesencephalic sulcus and inferiorly by the pontomedullary sulcus. Its posterior surface is limited cranially by an imaginary line that courses below the inferior colliculi and caudally by an imaginary line that courses at the level of the lateral angles of the fourth ventricle, ending laterally at another arbitrary parasagittal line that surrounds the emergence of the trigeminal nerve. . $2,43,49,51^{2}$

Anterior Surface. The anterior surface of the pons rests over the anterior portion of the clivus. It is convex in its transverse section and is continuous with the middle cerebellar peduncle (brachium pontis) on each side, having as an arbitrary limit the emergence of the trigeminal nerve on each side. The basilar sulcus is located anteriorly along its midline, with the pyramids formed by the pyramidal tracts situated on both sides. The posterior root of the trigeminal nerve emerges from the upper portion of the middle cerebellar peduncle just below the anterior angle of the cerebellum. The nerve consists of 2 roots: the larger root is the sensory nerve root, and the smaller one is the motor nerve root.

Posterior Surface, Lateral Surfaces, and Superior and Inferior Extremities. The posterior surface forms the superior part of the floor of the fourth ventricle, also known as the rhomboid fossa, and it is covered by the cerebellum. The lateral surfaces are continuous with the middle cerebellar peduncles. The superior extremity is continuous with the cerebral peduncles, and the inferior extremity is continuous with the base of the medulla oblongata. $23,29,36,43,49$

\section{Internal Morphology}

The pons is morphologically and physiologically divided into 2 portions: the anterior part or base and the posterior part or tegmentum. The trapezoid body, a bundle of transverse myelinated fibers, is located between these 2 parts. ${ }^{22,49}$

Base or Crus of the Pons. The anterior part, base, or crus of the pons is the extension of the cerebral peduncles and continues as the pyramid of the medulla oblongata. It is formed by longitudinal bundles that constitute the pyramidal path, by transverse fibers that constitute the origin of the middle cerebellar peduncles, and by the pontine nuclei, which surround the other fibers.

Transverse Fibers. There are 2 types of transverse fibers: 1) fibers from the pons to the cerebellum (pontocerebellar fibers) that course through the middle cerebellar peduncles and pass through the pyramidal pathway, and 2) fibers from the acoustic pathway, constituting the trapezoid body. ${ }^{43,49}$ The transverse fibers that connect the pons with the cerebellum are divided into 3 layers ${ }^{49}: 1$ ) the superficial layer (stratum superficiale pontis), anterior to of the pyramidal path and with the deep surface covered by the pontine nuclei; 2) the intermediate layer (stratum complexum), which separates the bundles of the pyramidal pathway (Figs. 10 and 11); and 3) the deep layer (stratum profundum pontis), which courses behind the pyramidal pathway and in front of the medial lemniscus.

Longitudinal Fibers. The longitudinal fibers can be divided into corticospinal, corticonuclear, and corticopontine fibers. The corticospinal tract at the base of pons forms several separated bundles and does not have the compact structure observed in the medullary pyramids. The corticonuclear tract represents cortical fibers directed to the facial, trigeminal, and abducent nuclei. The corticopontine fibers originate from the cerebral cortex and end at the pontine nuclei from which the pontocerebellar fibers originate (Figs. 10-12). ${ }^{22,43,49}$

Pontine Nuclei. The pontine nuclei are small groups of neurons scattered throughout the base of the pons.

Tegmentum. The posterior part of the pons, also called the tegmentum, is similar in structure to the medulla oblongata and to the tegmentum of the midbrain, with which it is continuous. It is composed of the reticular substance (substance of Deiters ${ }^{49}$ ) and wraps around ascending, descending, and transverse fibers, in addition to cranial nerve nuclei and gray matter of the pons..$^{29,30,43,49}$

Gray Matter. The gray matter of the pons can be grouped into gray matter homologous to the spinal cord (nuclei of cranial nerves) and the pontine's own gray matter (pontine nuclei, the superior olive, and the gray matter of the reticular formation). Topographically there are mainly 3 groups of nuclei: The first group occupies the external part of the pons and corresponds to the nuclei of the cranial nerves: the facial nucleus and the motor and sensory portions of the trigeminal nerve (internal column and external column, respectively). The second group is represented by the superior olive, the nuclei of the trapezoid body, and the nuclei of the lateral lemniscus. The third group is represented by the central gray matter that covers the posterior surface of the reticular formation and consists of a medial column that gives rise to the CN VI nucleus and a lateral column that gives rise to the vestibular nerves, which end in the vestibular nuclei. ${ }^{43,49}$ The nuclei of cranial nerves that constitute the homologous gray matter represent the base or head of the anterior horn (in the case of motor nerves) and of the posterior horn (for sensory nerves) and include the facial nucleus, the abducent nucleus, the trigeminal nuclei, and the vestibulocochlear nuclei. 

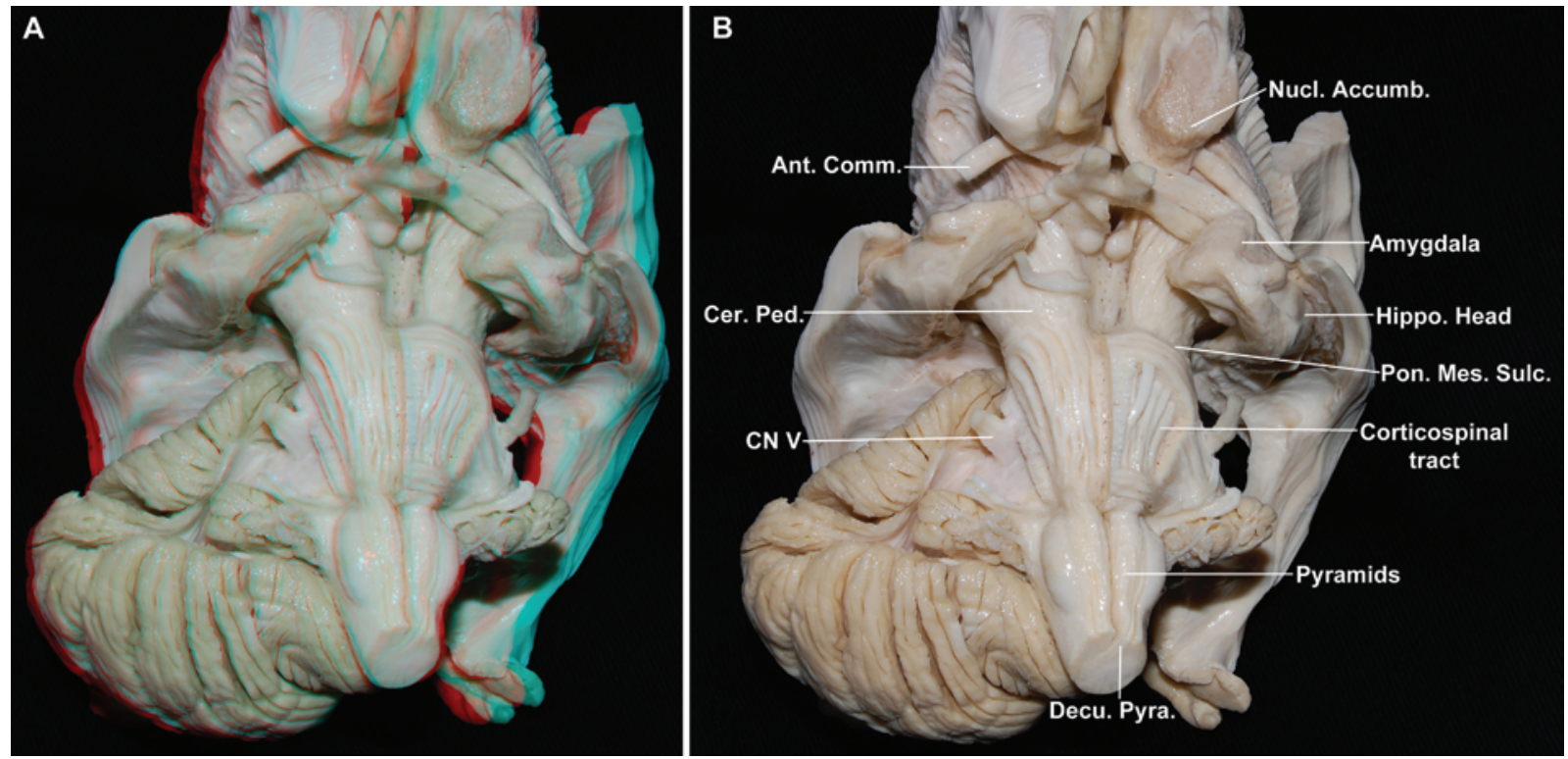

FIG. 10. 3D (A) and 2D (B) images. The course of the pyramidal pathway is seen until its decussation at the inferior limit of the medulla oblongata. The stratum superficiale pontis was completely removed on the right and partially removed on the left, to show that the corticospinal fibers are fragmented by the fibers of the stratum complex. Ant. Comm. = anterior commissure; Cer. Ped. = cerebral peduncles; Decu. Pyra. = decussation of the pyramids; Hippo. Head = head of the hippocampus; Nucl. Accumb. = nucleus accumbens; Pon. Mes. Sulc. = pontomesencephalic sulcus. Figure is available in color online only.

The facial nucleus is a mixed nucleus. The sensory root is represented by the intermediate nerve (nerve of Wrisberg ${ }^{49}$ ); the motor nucleus is pontomedullary, located behind the trapezoid body and deep to the trigeminal nerve root, and is separated from the floor of the fourth ventricle by a space of approximately $4 \mathrm{~mm} .{ }^{49}$ The fibers originate from the motor nucleus of the facial nerve and circle the abducent nucleus (forming the inner genu of the facial nerve) and constitute the round eminence or facial colliculus on the floor of the fourth ventricle. The motor nucleus is responsible for innervation of the muscles of the face, and injury to this nucleus causes facial paralysis of the inferior motor neuron type..$^{14,43,49}$ The sensory fibers course to the geniculate ganglion and end at the solitary tract nucleus (Nageotte's gustatory nucleus ${ }^{49}$ ); these fibers are responsible for the sense of taste in the anterior twothirds of the tongue.

The abducent nucleus is a motor nucleus that, together with the inner genu of the facial nerve, constitutes the round eminence. It innervates the lateral rectus muscle of the ocular globe and damage to it results in ipsilateral paralysis of abduction of the ipsilateral eye. ${ }^{14}$

The sensory nucleus, mesencephalic tract nucleus, and motor nucleus of the trigeminal nerve are situated at the pons. The sensory nucleus is located lateral to the motor nucleus and corresponds to the enlarged cranial extension of the spinal tract nucleus. The mesencephalic tract nucleus extends cranially from the sensory nucleus, toward the
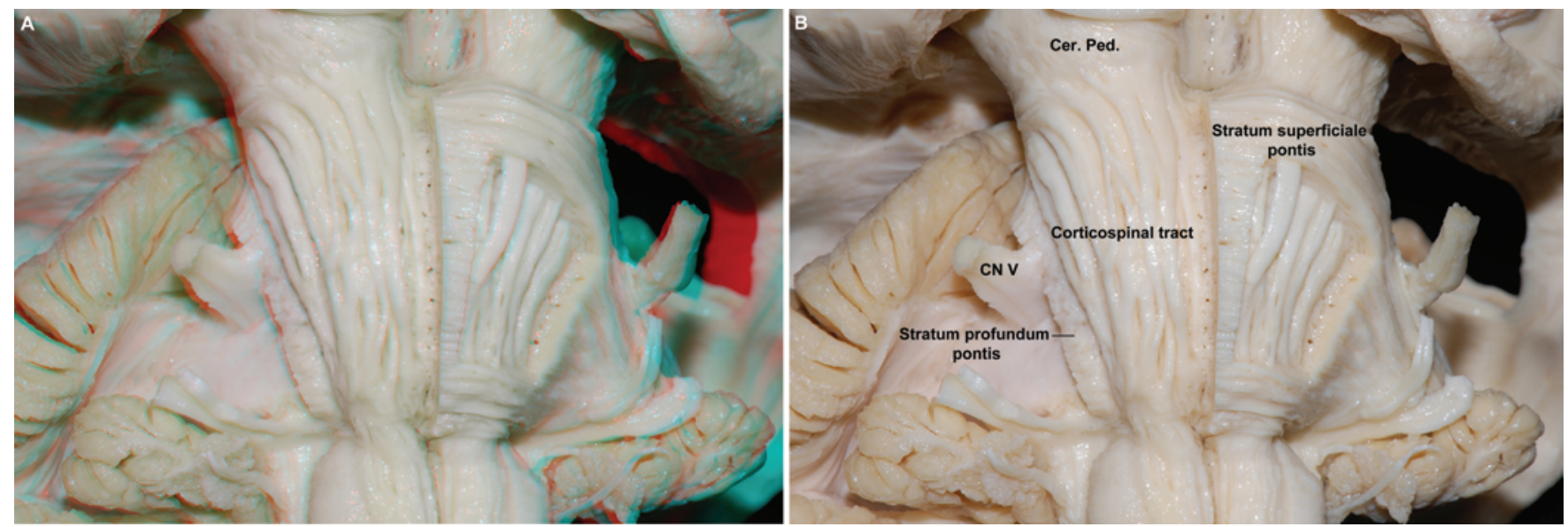

FIG. 11. 3D (A) and 2D (B) images. Magnified view, at the level of the pons. Cer. Ped. = cerebral peduncles. Figure is available in color online only. 

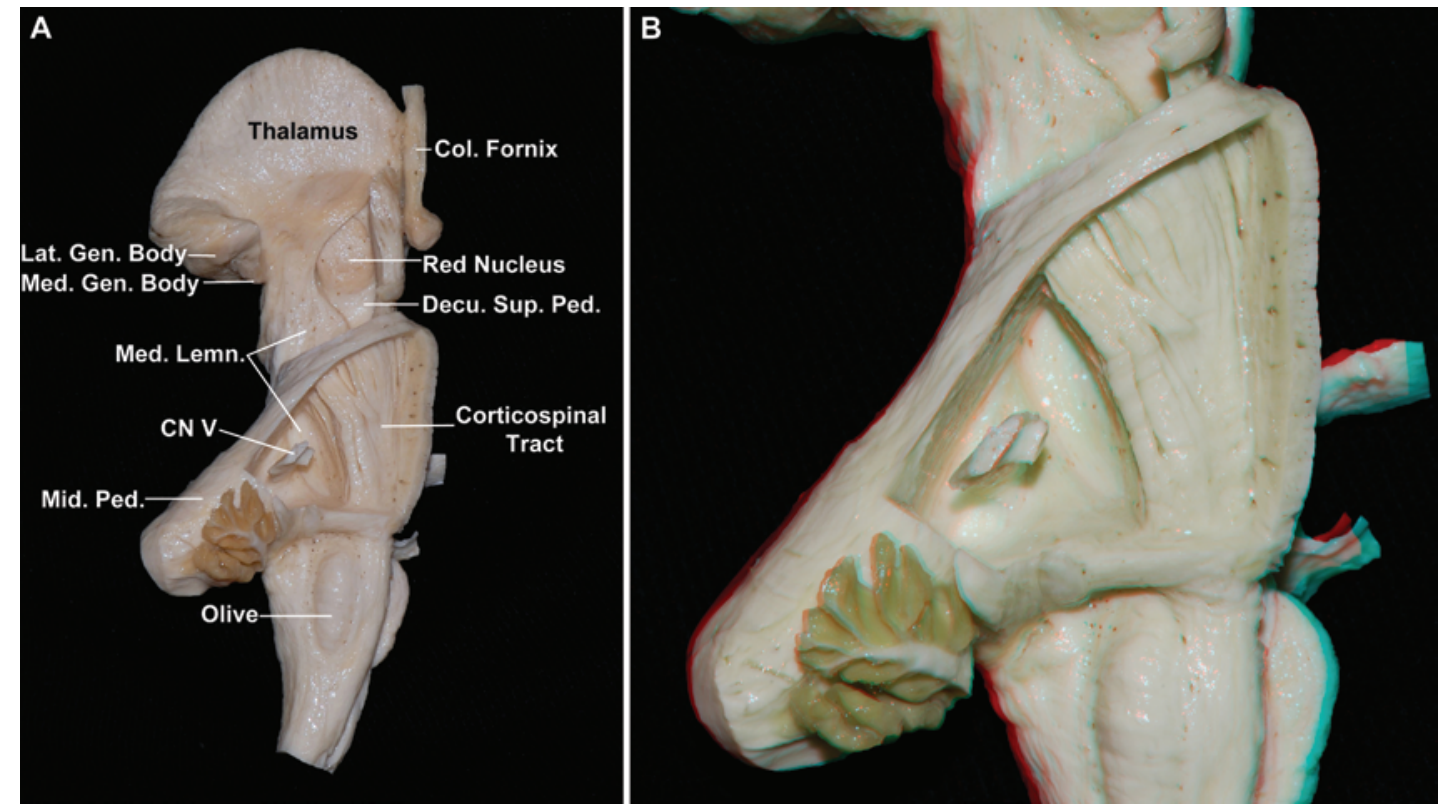

FIG. 12. A: Right anterolateral view of the brainstem. The main anatomical landmarks were exposed for surgical planning (CN V, pyramidal pathway, and medial lemniscus [Med. Lemn.]). Col. Fornix = columns of the fornix; Decu. Sup. Ped. = decussation of the superior cerebellar peduncle; Lat. Gen. Body = lateral geniculate body; Med. Gen. Body = medial geniculate body; Mid. Ped. = middle cerebellar penuncle. B: Image in 3D. Magnified view of the same specimen, at the level of pons, exposing the peritrigeminal area. Figure is available in color online only.

midbrain. The sensory nucleus also extends to the medulla, where it is called the spinal trigeminal nucleus. This nucleus is responsible for the deep proprioception sensation of the masticatory muscles, gum, and temporomandibular joint; the pontine sensory nucleus and its axons join the medial lemniscus; and the spinal nucleus is responsible for the sensations of pain, temperature, and crude touch. The motor nucleus gives rise to fibers to the masticatory muscles, and thus it can also be called the masticator nucleus.

The tegmentum harbors the ventral and dorsal cochlear nuclei of CN VIII. The dorsal nucleus forms a prominence called the acoustic tubercle at the lateral angle of the floor of the fourth ventricle, and its axons are visible as acoustic striae that dive into the stem of the calamus and cross the midline to end at the nuclei of the reticular formation. The fibers of the ventral nucleus have a horizontal course and decussate and form the trapezoid body, which ascends around the superior olivary nucleus as the lateral lemniscus. These components take part in the hearing process by receiving fibers from the spiral organ (organ of Corti). ${ }^{43,49}$

There are 4 vestibular nuclei (superior, inferior, medial, and lateral) located in the vestibular area (external white wing) of the floor of the fourth ventricle..$^{14,29,30,43,49,51}$ They receive nerve impulses from the vestibular part of the inner ear that course through the vestibular ganglion (Scarpa's ganglion) ${ }^{43,49}$ and reach the vestibular nuclei by the vestibular fibers of CN VIII. Damage causes vertigo, postural instability, and nystagmus. ${ }^{14}$

The pontine gray matter consists of the pontine nuclei, the superior olivary nucleus, the nucleus of the trapezoid body, the nucleus of the lateral lemniscus, and the gray matter of reticular formation..$^{4,43,49}$

Nuclei of the parasympathetic nervous system include the superior salivary nucleus (parasympathetic innervation of the sublingual and submandibular glands) and the lacrimal nucleus (parasympathetic innervation of the lacrimal, nasal, and palatine glands).

White Matter. The fibers located in the pons can be grouped into transverse and longitudinal fibers.

The transverse fibers originate from the ventral cochlear nucleus, cross the midline, and constitute the trapezoid body, which continues ascending as the lateral lemniscus. ${ }^{21,22,30,43,49}$ The fibers from the dorsal cochlear nucleus form the acoustic striae (medullary striae), which course along the floor of the fourth ventricle and join the trapezoid body.

The longitudinal fibers of the pontine tegmentum can be grouped in ascending, descending, and associative fibers. The ascending fibers are the medial, lateral, trigeminal, and spinal lemnisci, and the superior cerebellar peduncle. The medial lemniscus is a triangular area located behind the pyramidal pathway and close to the raphe. It is formed by medullary sensory fibers that connect the gracile (Goll's ${ }^{49}$ ) and cuneate (Burdach's ${ }^{49}$ ) nuclei to the thalamus. It serves conscious proprioception and touch and is completed by the lateral spinothalamic tract, which carries the sensations of pain and temperature (Figs. 12 and 13). ${ }^{29,30,43,49}$

The lateral lemniscus (lateral band of Reil ${ }^{49}$ ) consists of fibers of the trapezoid body that change direction and ascend toward the inferior colliculus. It is located in the anterior portion of the pontine tegmentum, lateral to the spinothalamic tract and medial to the trigeminal motor fibers. It is part of the acoustic pathway.

The trigeminal lemniscus consists of fibers that originate in the spinal trigeminal nucleus and principal sensory 

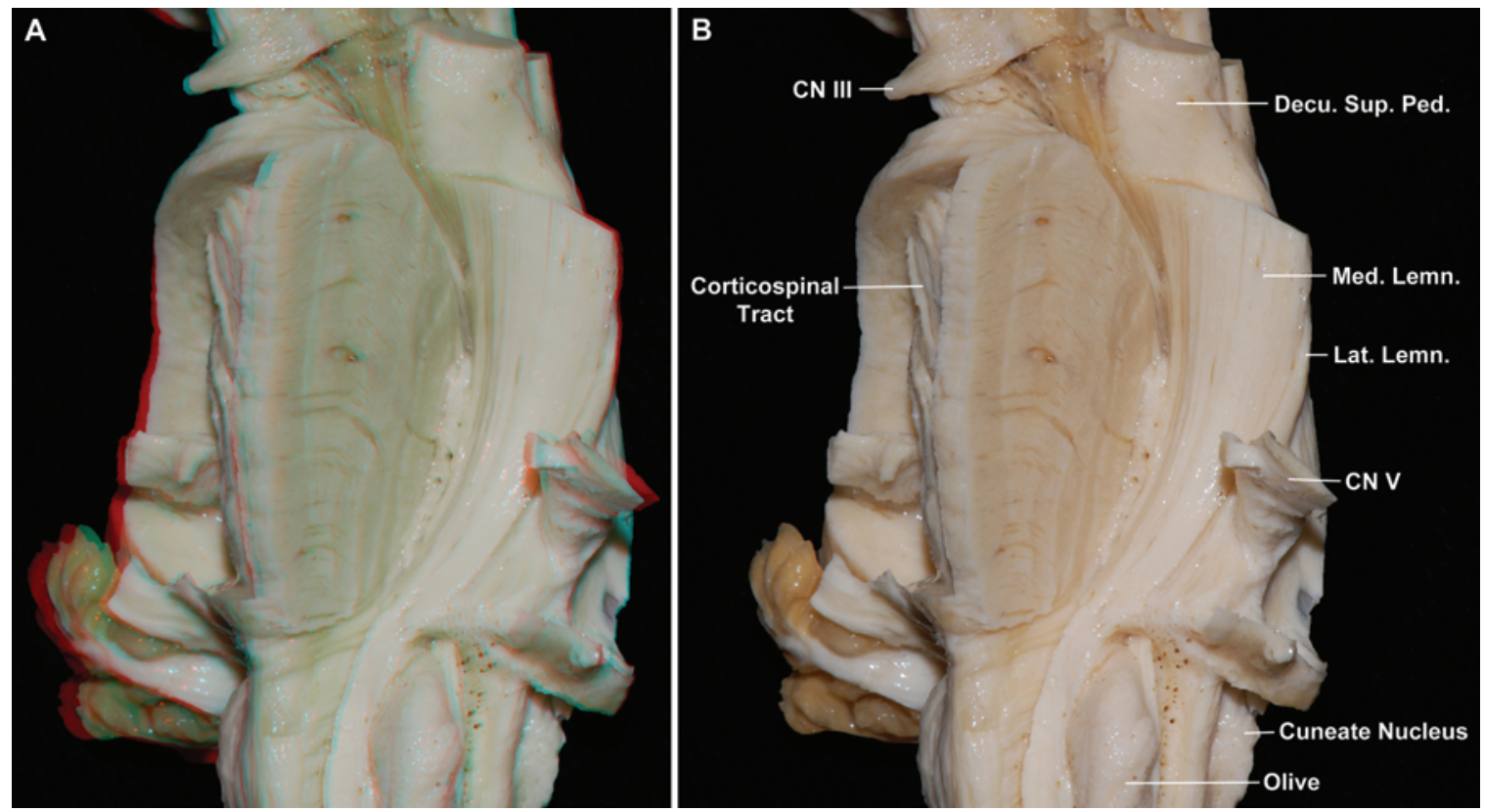

FIG. 13. 3D (A) and 2D (B) images. Left anterolateral view of the pons, exposing the medial lemniscus (Med. Lemn.), which is located behind the trapezoid body, in front of the medial longitudinal fasciculus, and medial to CN V. Decu. Sup. Ped. = decussation of the superior cerebellar peduncle; Lat. Lemn. = lateral lemniscus. Figure is available in color online only.

trigeminal nucleus and end in the ventral posteromedial nucleus of the thalamus.

The spinal lemniscus is formed by the union of the anterior and lateral spinothalamic tracts, and it is situated at the anterior portion of the pontine tegmentum, between the lateral and medial lemnisci. The superior cerebellar peduncle consists mainly of efferent fibers of the cerebellum. The most important of these fibers form the dentatorubral tract, which originates in the dentate nucleus and reaches the upper pontine tegmentum where the fibers decussate with the opposite side, forming the decussation of the superior peduncle (Wernekinck's) on their way to the red nucleus at the midbrain.

The descending fibers include the tectospinal, rubrospinal, vestibulospinal, trigeminal spinal, and central tegmental tracts. The tectospinal tract originates from the superior colliculus (which receives fibers from the visual cortex and retina) and ends at the upper cervical spinal cord. The rubrospinal tract consists of extrapyramidal fibers involved in motor control but is poorly developed in humans. The vestibulospinal tract originates from vestibular nuclei and carries impulses related to balance control to spinal motor neurons. The trigeminal spinal tract consists of sensory fibers that enter the brainstem through the trigeminal nerve and have a downward course along the spinal trigeminal nucleus. The tract is placed laterally to the respective nucleus and they extend over the pons, medulla, and upper part of the spinal cord. The central tegmental tract courses from the red nucleus to the medullary olive. It forms a capsule of myelinated fibers around the olive, which is known as the amiculum.

The association fibers correspond to the medial longitudinal fasciculus, which is situated at the posterior part of the tegmentum, under the floor of the fourth ventricle, lat- erally to the midline and posteromedially to the reticular formation. It contains ascending and descending association fibers that participate in the reflex association pathway that allows associated movements of the eyes, head, and neck, with a starting point at the retina and organ of Corti. $22,29,30,43,49$

\section{Medulla Oblongata}

Also called the medulla, the medulla oblongata is the most inferior part of the brainstem, representing a transition between the spinal cord and the encephalon..$^{22,43,49}$

\section{External Morphology and Relationships}

The medulla has a conical shape with its base oriented superiorly, continuous with the pons. It is limited superiorly by the pons and inferiorly by a horizontal plane that courses just below the decussation of pyramids, above the first cervical spinal nerve. The bone limit of the transition between the spinal cord and medulla is a plane that links the middle part of the anterior arch of the atlas with the superior border of the posterior arch. ${ }^{49}$ Its average measurements are $27-30 \mathrm{~mm}$ in length, $12-15 \mathrm{~mm}$ in anteroposterior diameter, $20-25 \mathrm{~mm}$ in transverse diameter on the superior extremity, and $10-12 \mathrm{~mm}$ at the inferior extremity (Fig. 1). ${ }^{43,49}$

Anterior Surface. The midline shows the anterior median sulcus, which ends superiorly at the pontomedullary junction as the inferior foramen cecum (foramen of Vicq-d'Azyr). ${ }^{49}$ This sulcus is interrupted inferiorly by the decussation of pyramids and extends for about $6-8$ $\mathrm{mm}$ (Fig. 14). The anterior pyramids are located on each side of the anterior median sulcus. CN VI emerges from the pontomedullary sulcus anterior to the pyramids. The medullary olive is placed laterally and is separated from 

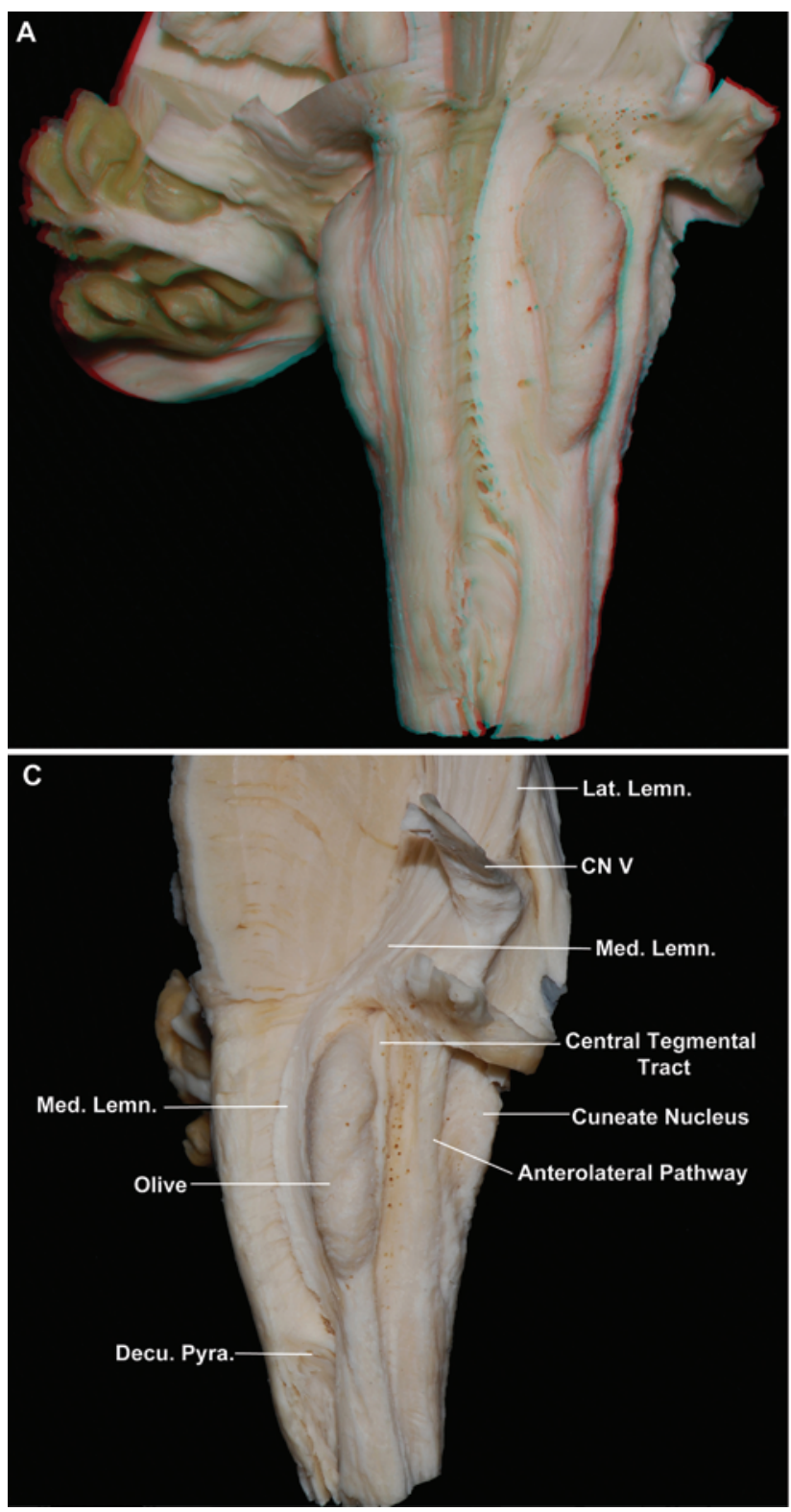

the pyramid by the anterolateral sulcus, also called the preolivary sulcus or hypoglossal sulcus. The other lower cranial nerves (glossopharyngeal, vagus, and accessory) originate from the posterolateral sulci at the dorsal border of the olives..$^{9,14,29,43,49}$

Posterior Surface. The posterior surface of the medulla oblongata is divided into superior and inferior parts. The superior part represents, on the midline, the inferior half of the fourth ventricle and, laterally, the inferior cerebellar peduncle. The inferior part is divided into 2 halves by the posterior median sulcus. Each half comprises the gracile tubercle and fasciculus situated medially and the cuneate tubercle and fasciculus laterally; these structures are separated by the posterior intermediate sulcus.

Lateral Surfaces. The lateral surfaces are limited by the anterolateral sulcus anteriorly and by the posterolateral sulcus posteriorly, and are formed by the lateral cord of the medulla. The lateral surfaces are covered anteriorly

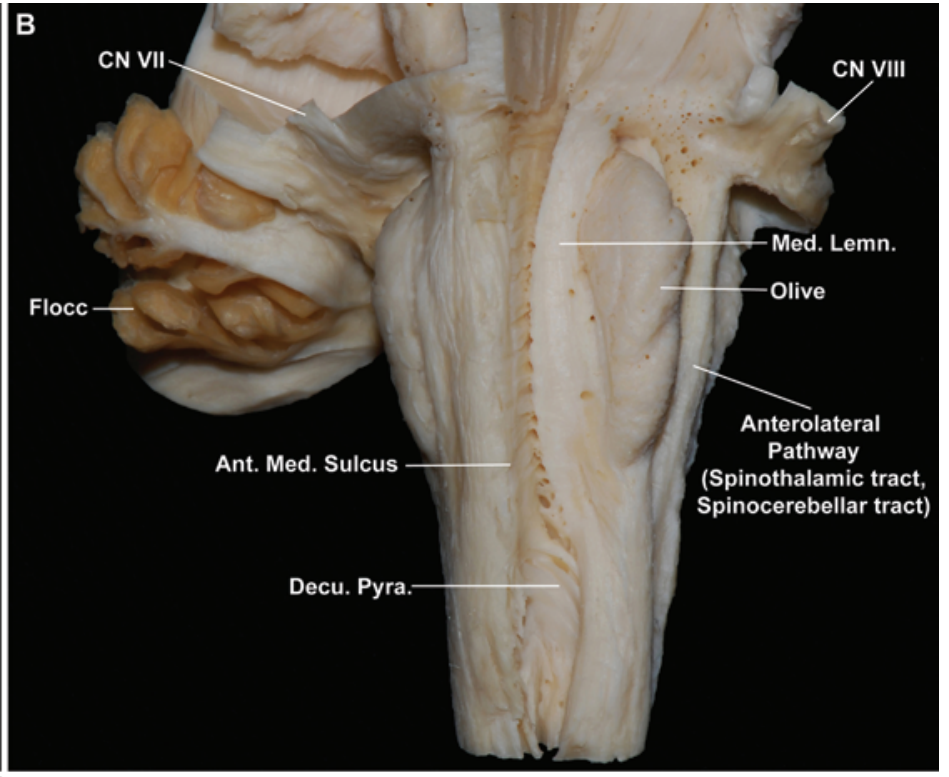

FIG. 14. 3D (A) and 2D (B) images. Anterolateral view of the medulla oblongata. The left medullary pyramid was removed to identify the medial lemniscus (Med. Lemn.). C: Lateral view of the medulla, same specimen. Ant. Med. Sulcus = anterior median sulcus; Decu. Pyra. = decussation of the pyramids; Flocc $=$ flocculus; Lat. Lemn. $=$ lateral lemniscus. Figure is available in color online only.

on the superior half by the medullary olive. The superior extremity does not reach the pons, being separated by a depression called the supraolivary fossa, which is the apparent origin of the facial and intermediate (nerve of Wrisberg) nerves. The olive occupies only the anterior part of the lateral cord. A narrow space with a depression is located behind the supraolivary fossa, and is called the lateral medullary fossa, from which the vestibulocochlear nerve arises..$^{9,14,29,43,49}$

\section{Internal Morphology}

The internal organization of the lower medulla is similar to that of the spinal cord; however, the structure of the upper regions of the medulla shows significant changes in relation to the spinal cord, which are caused mainly by the nuclei of the medulla, the decussation of the pyramids or motor decussation, the lemniscal decussation or sensory decussation, and the opening of the fourth ventricle. ${ }^{22,29,30,43,49}$ 
Gray Matter. The gray matter of the medulla can be categorized as gray matter homologous to the spinal cord (nuclei of cranial nerves) and the medulla's own gray matter (inferior olive, gracile and cuneate nuclei, medial and dorsal accessory olivary nuclei, and gray matter of the reticular formation).

The gray matter homologous to the spinal cord includes the ambiguous nucleus (or anterolateral nucleus of Stilling ${ }^{49}$ ), from which arise efferent visceral fibers to CNs IX (glossopharyngeal), X (vagus), and XI (accessory), for innervation of muscles of the pharynx and larynx; the hypoglossal nucleus, from which motor fibers for innervation of the tongue arise; the dorsal motor nucleus of the vagus, a parasympathetic motor nucleus where preganglionic neurons whose axons leave the vagus nerve are situated; the vestibular nuclei, which are sensory nuclei that receive fibers entering the brainstem through the vestibular part of CN VIII; the solitary tract nucleus, a sensory nucleus that receives the afferent visceral fibers of CNs VII, IX, and X, after a descending course through the solitary tract; the spinal trigeminal nucleus, where somatic afferent fibers bringing sensation of almost the entire head arrive; and the inferior salivary nucleus, which is the origin of preganglionic fibers that follow through the glossopharyngeal nerve for innervation of the parotid gland.

The medulla's own gray matter contains the gracile and cuneate nuclei, the inferior olivary nucleus, and the medial and dorsal accessory olivary nuclei. The internal arcuate fibers originate from the gracile and cuneate nuclei and cross the midline to ascend as the medial lemniscus. The gracile and cuneate nuclei are represented on the surface as the gracile and cuneate tubercles, respectively. The inferior olivary nucleus appears on axial sections as a very pleated sheet with a medial opening (Fig. 14C) and receives input from the cerebral cortex, spinal cord, and red nucleus. It connects to the cerebellum through olivocerebellar fibers that cross the midline and end at the cerebellar cortex after coursing through the inferior cerebellar peduncle. These structures play a role in motor learning. The inferior olivary nucleus corresponds on the surface to the medullary olive. ${ }^{22,43,49}$ The medial and dorsal accessory olivary nuclei have basically the same structure, connections, and function as the inferior olivary nucleus, forming together the inferior olivary complex.

White Matter. The anterolateral cord harbors the 2 pyramidal fasciculi, the straight cerebellar fasciculus, Gowers's fasciculus, and the ascending anterolateral fasciculus. The posterior cord harbors the gracile and cuneate fasciculi. These fibers can be grouped into transverse and longitudinal fibers.

The transverse fibers of the medulla are also called arcuate fibers and can be divided into internal and external fibers. The internal arcuate fibers contain the axons of the gracile and cuneate nuclei on their course to the medial lemniscus and the olivocerebellar fibers. The external arcuate fibers course on the surface of the medulla and enter the cerebellum through the inferior cerebellar peduncle.

The longitudinal fibers of the medulla tegmentum can be grouped into ascending, descending, and associative fibers.

The ascending fibers are the gracile (Goll's $\left.{ }^{49}\right)$ and cu- neate (Burdach's ${ }^{49}$ ) fasciculi, the medial lemniscus, the lateral and anterior spinothalamic tracts, the anterior spinocerebellar tract, the posterior spinocerebellar tract, and the inferior cerebellar peduncle.

The gracile (Goll's ${ }^{49}$ ) and cuneate (Burdach's ${ }^{49}$ ) fasciculi contain fibers from the sensory roots of the spinal nerves. The gracile fasciculus carries information from the lower limbs, pelvis, abdomen, and inferior part of the chest. The cuneate fasciculus carries information from the superior part of the chest, upper limbs, and neck. The middle part of the medulla harbors the nuclei of these fasciculi, and fibers arising from them are called the internal arcuate fibers, representing the origin of the second sensory neuron, which constitutes the initial portion of the medial lemniscus (Fig. 14). 14,29,30,43,49

The medial lemniscus carries information from the gracile and cuneate fasciculi to the ventral posterolateral nucleus of the thalamus. It is situated near the midline, posterior to the corticospinal tract, and anterior to the tectospinal tract (Fig. 14).

The lateral and anterior spinothalamic tracts are situated on the lateral area of the medulla, medial to the ventral spinocerebellar tract. The anterior spinothalamic tract carries poorly discriminative sensory information (protopathic touch, crude touch, and other sensations not known for accurate localization, such as itch, tickle, and sexual feelings). The lateral spinothalamic tract carries pain and temperature information from skin, bones, joints, and muscles, and feelings of vesical filling and urge to urinate (Fig. 14C).

The anterior spinocerebellar tract (Gowers' fasciculus ${ }^{49}$ ) is situated superficially on the lateral area of the medulla, between the olivary nucleus and the posterior spinocerebellar tract. It is a crossed (contralateral) spinocerebellar pathway that reaches the vermis through the superior cerebellar peduncle and the superior medullary velum. It carries unconscious proprioception information from the lower limbs and trunk and is visible on the superior cerebellar peduncle.

The posterior spinocerebellar tract (Flechsig's fasciculus $^{49}$ ) is situated superficially on the lateral area of the medulla, between the anterior spinocerebellar tract and the inferior cerebellar peduncle. It is a straight (ipsilateral) spinocerebellar pathway that reaches the vermis through the inferior cerebellar peduncle. It carries unconscious proprioceptive information from the lower limbs.

The inferior cerebellar peduncle (restiform body) is situated on the lateral borders of the inferior half of the fourth ventricle until the lateral recesses, where the fibers flex dorsally to penetrate the cerebellum. It is composed of olivocerebellar fibers, fibers from the posterior spinocerebellar tract, and external arcuate fibers.

The descending fibers include the corticospinal tract, corticonuclear tract, extrapyramidal tracts, spinal trigeminal tract, and solitary tract. The fibers of the corticospinal tract originate from the cerebral cortex and are directed to the spinal cord, occupying the anterior portion of the medullary pyramids. They undergo an incomplete decussation, giving rise to a straight or ipsilateral or anterior pyramidal fasciculus, which continues on its course on the anterior cord and gives rise to a crossed or lateral pyramidal fas- 
ciculus that follows on the lateral cord (Fig. 14). Damage to the corticospinal tract causes contralateral hemiplegia.

The fibers in the corticonuclear tract originate from the cerebral cortex and are directed to the motor nuclei of cranial nerves (ambiguous and hypoglossal nuclei), occupying the posterior and medial portions of the medullary pyramids.

The fibers of the extrapyramidal tracts (tectospinal, rubrospinal, vestibulospinal, and reticulospinal tracts) originate from several regions of the brainstem and are directed to the spinal cord. The spinal trigeminal tract is formed by trigeminal sensory fibers and descends laterally to the spinal trigeminal nucleus.

The solitary tract is formed by visceral afferent fibers that enter the brainstem through CNs VII, IX, and X and descend along the solitary tract nucleus.

The association fibers are the medial longitudinal fasciculus. This fascicle is located along the entire length of the brainstem, always occupying a posterior and medial position. At the medulla, it is placed posterior to the tectospinal tract.

Important autonomic centers are also found in the white and gray matter of the medulla oblongata, such as the breathing center at the level of the reticular formation, the vasomotor center that controls cardiovascular functions, the vomit center on the area postrema at the level of the posterior nucleus of the vagus nerve, and the centers for cough and hiccup..$^{14,22,29,30,43,49}$

\section{Floor of the Fourth Ventricle}

\section{General Considerations}

The floor of the fourth ventricle, also called the rhomboid fossa, ${ }^{22}$ is created by the pons on its superior twothirds and by the medulla on its inferior one-third. It is limited superolaterally by the superior cerebellar peduncles, which are also called conjunctival brachia, and inferolaterally by the inferior cerebellar peduncles and gracile and cuneate tubercles. Its cranial apex is at the level of the cerebral aqueduct; its caudal tip, the obex, anterior to the foramen of Magendie; and its lateral angles open through the lateral recesses and foramina of Luschka into the cerebellopontine angles. ${ }^{22,23,36,49}$

\section{Constituent Parts}

The floor of the fourth ventricle can be divided in 3 parts: superior or pontine (also called the superior triangle), intermediate or junctional, and inferior or medullary (also called the inferior triangle). ${ }^{23,36}$ The superior part has a triangular shape with its apex toward the cerebral aqueduct and its base represented by an imaginary line that connects the inferior border of the inferior cerebellar peduncles. The intermediate part is located between the border of the inferior cerebellar peduncles and the juncture of the tela choroidea with the teniae, just below the lateral recess. The inferior part has a triangular shape and is limited laterally by the teniae. Its caudal apex, called the obex, is located anterior to the foramen of Magendie.

The floor of the fourth ventricle is divided longitudinally by the dorsal median sulcus and laterally by the sulcus limitans. This is another longitudinal sulcus that divides each half of the floor of the fourth ventricle into a medial salient band, termed the medial eminence, and a lateral region called the vestibular area. The sulcus limitans separates the motor nuclei derived from the basal plate of the neural tube and situated medially from the sensory nuclei derived from the alar plate and located laterally. This sulcus is discontinuous and it becomes deeper at 2 places, where it gives rise to the superior and inferior foveae of the rhomboid fossa. The superior fovea is related to the motor nucleus of the trigeminal nerve; thus this fovea is also called the trigeminal fovea. ${ }^{49}$ The locus coeruleus is located in front of the superior fovea. The inferior fovea is characterized by a triangular dark area, the vagal trigone (Fig. 15). ${ }^{23-25,36,49}$

The inferior or medullary triangle is a small triangular depression on the floor of the fourth ventricle (also known as the calamus scriptorius, because Herophilus compared this region to the tip of a reed stylus). ${ }^{14,41,49}$ The median sulcus forms the calamus stem, which becomes deeper at its inferior extremity, at the entrance of the ependymal conduit (Arancio's ventricle ${ }^{49}$ ). The gray commissure of the medulla forms a transverse leaf behind the tip that is called the obex. The acoustic striae represent the beards of the calamus ${ }^{49}$ and consist of white strings with a transverse direction that usually follow from the superior half of the triangle, above the hypoglossal trigone, toward the midline, and then disappear at the posterior median sulcus. The acoustic tubercle forms a prominence at the lateral part of the vestibular area.

The inferior trigone consists of 3 different areas. The hypoglossal trigone (internal white wing) covers the hypoglossal nucleus and forms a triangular eminence with a superior base. The vestibular area (external white wing) occupies the external portion of the medullary trigone and also is triangular with a superior base. It consists of gray matter and represents the place where vestibular and cochlear connections end, and is thus called the acoustic trigone. The inferior fovea (gray wing) is situated between the 2 white wings. It is triangular with an inferior base parallel to the inferior cerebellar peduncle and covers the dorsal nucleus of the vagus nerve, harboring the nuclei of the glossopharyngeal and vagus nerves. The area postrema is a tongue-shaped area located between the funiculus separans and the gracile tubercle, rostral to the obex (Fig. 15). ${ }^{43,49}$

The superior or pontine triangle appears on either side of the superior aspect of the median sulcus as an oval eminence about $4 \mathrm{~mm}$ in diameter. ${ }^{49}$ This is termed the facial colliculus (round eminence) and covers the abducent nucleus and the ascending portion of the facial nerve. This eminence continues upward as a longitudinal cord called the funiculus teres, which reaches the aqueduct of Sylvius. The superior fovea is located beside the external face of the round eminence. Ahead of this fovea is placed the locus coeruleus, a gray prominence of 5-6 $\mathrm{mm}$ associated with the sleep mechanism. ${ }^{23-25,36,43,49}$

\section{Discussion Surgical Considerations}

Although still a major challenge, surgical treatment of 

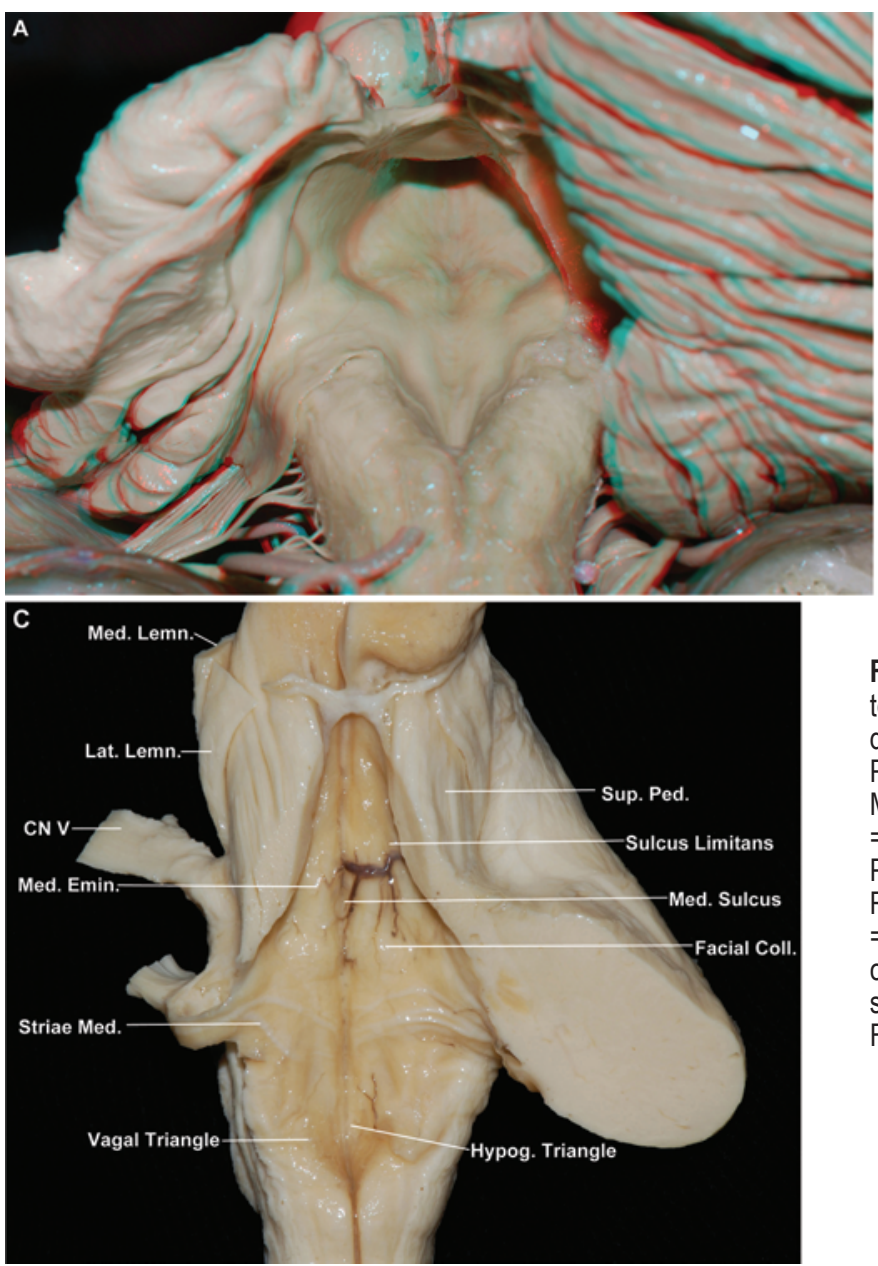

brainstem lesions has recently been made possible in many circumstances because of developments in microneurosurgical technique, neuroimaging, neuroanesthesiology, neuromonitoring, and neurointensive care. Nevertheless, to plan and perform delicate brainstem procedures with the aid of all these tools and support, the modern neurosurgeon must have as a fundamental requirement a thorough knowledge of the brainstem architecture and functional anatomy.

In this dissection study, our main aim was to study and describe the intrinsic architecture of the brainstem, more particularly in relation to possible surgical approaches.

The criteria for operating on brainstem lesions depend mainly on the nature of the lesion, on its topography, and on the surgeon's experience. Preoperative planning of the surgical strategy requires careful evaluation of the functions of the cranial nerves, nerve tracts, and cerebellar function.

Intraoperative monitoring includes auditory evoked potentials (testing the lateral lemniscus), somatosensory evoked potentials (testing the medial lemniscus), motor evoked potentials for the evaluation of the corticospinal pathway, and mapping of CNs VII, IX, X, and XII on the floor of the fourth ventricle to identify its safest entry zones. It is important to keep in mind that the mapping of the brainstem does not detect lesions of the corticospinal

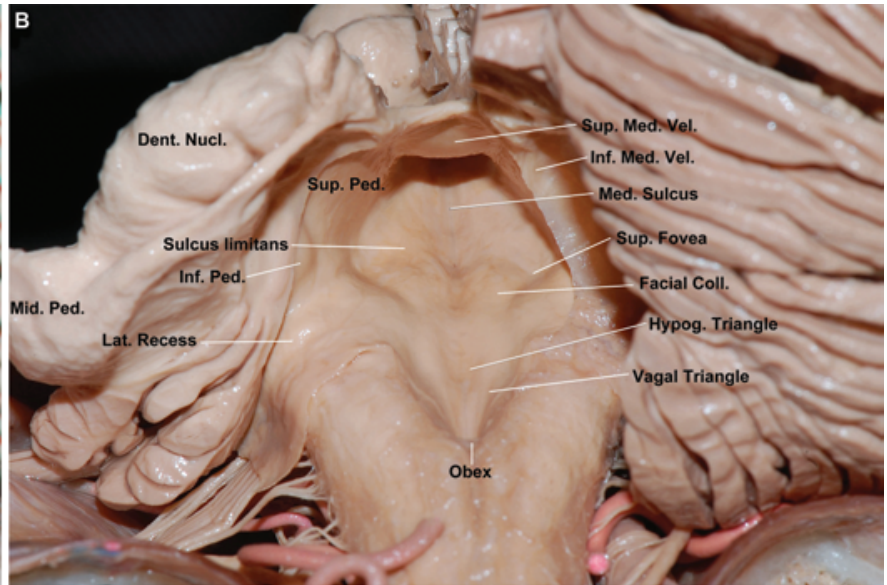

FIG. 15. 3D (A) and 2D (B) images. Floor of the fourth ventricle. The tonsils and left cerebellar hemisphere were removed, preserving the dentate nucleus (Dent. Nucl.), which is located just above the tonsil. Posterior view of the brainstem (C). Floor of the fourth ventricle. Striae Med. = striae medullaris; Facial Coll. = facial colliculus; Hypog. Triangle = hypoglossal triangles; Inf. Med. Vel. = inferior medullary velum; Inf. Ped. = inferior cerebellar peduncle; Lat. Lemn. = lateral lemniscus; Lat. Recess = lateral recess; Med. Emin. = median eminence; Med. Lemn. $=$ medial lemniscus; Med. Sulcus = median sulcus; Mid. Ped. = middle cerebellar peduncle; Sup. Fovea = superior foveae; Sup. Med. Vel. = superior medullary velum; Sup. Ped. = superior cerebellar peduncle. Figure is available in color online only.

and corticonuclear pathways, which can be detected by monitoring motor evoked potentials. There is no technique for monitoring cerebellar function.

In the 20th century, knowledge of brainstem anatomy and physiology increased dramatically with studies that were done using immunohistochemical, electrophysiological, and immunological techniques. ${ }^{6,37,48}$ The nervous system began to be closely studied by researchers in many other branches of science. These studies answered many questions on how the brain works and helped to develop new examination modalities, such as CT and MRI. However, these modalities can never take the place of the fiber dissection technique in the education of a neurosurgeon. Neurosurgeons, who need to navigate more safely within the neuroanatomical structures, must learn surgical neuroanatomy in a way that helps them mentally picture this anatomy in 3 dimensions. The best way to do this is to become familiar with brain anatomy via the fiber dissection technique. This knowledge becomes more important when the target in question is the brainstem. Using the surgical microscope in the fiber dissection technique is helpful in several ways. ${ }^{50}$ First, under the magnification of the microscope, the fiber tracts and deep nuclei can be identified and followed with improved accuracy. Moreover, dissecting the brain under the microscope reveals delicate structures and connections to the human eye that cannot be demon- 
strated by photography, even with today's high-definition technology. Second, hand-eye coordination is greatly improved as the neurosurgeon practices frequently by performing cadaver brain dissection. Moreover, dissecting in a way that simulates the surgical approach helps in further understanding of the microsurgical anatomy. Especially for surgery of the brainstem, learning the anatomy by hands-on fiber dissection is far superior to studying sectional anatomy pictures.

The most appropriate surgical approach should provide an optimal exposure of the related surface of the brainstem. This choice must be based on anatomical and functional data, location and extension of the lesion, and the patient's clinical condition. ${ }^{1,26,32,39-41}$ Wide resection of bone may be required for the related craniotomy since nervous tissue retraction must be avoided even more than in other parts of the encephalon. . $^{1,18,22,26-28}$

For all this, a deep and precise knowledge of the topographic and functional anatomy of the brainstem is mandatory in order for the neurosurgeon to have in mind a 3D framework of the internal architecture of the brainstem, which will guide him or her throughout the surgical procedure.

\section{Approaches to the Midbrain}

For microneurosurgical purposes, the approaches to the midbrain require particularly the understanding of the following structures, from anterior to posterior and from lateral to medial: pyramidal tract, medial and lateral lemnisci, medial geniculate body, medial longitudinal fasciculus, red nucleus, and the real and apparent origins of $\mathrm{CNs}$ III and IV.

Lesions located at the anterior surface of the midbrain (interpeduncular fossa and cerebral peduncles) can usually be accessed through a transsylvian approach using a classic pterional craniotomy ${ }^{53,54,56}$ or an orbitozygomatic craniotomy. ${ }^{12,15,33,57}$ Considering the risk of injury to the vein of Labbé due to retraction of the temporal lobe, ${ }^{7,8,14,41} \mathrm{oc}-$ casionally a subtemporal transtentorial approach may be more appropriate in selected cases (Fig. 16A) that require the division of the tentorium posteriorly to the entrance of the trochlear nerve to expose the anterolateral surface of the midbrain and the upper third of the pons. It is also possible to expose these lesions through a pretemporal transcavernous approach. ${ }^{42}$

The main microsurgical anatomical landmark for this approach is the emergence of the oculomotor nerve from the interpeduncular fossa, and the safe entry zone is indicated by a small rectangular area lateral to CN III, between the posterior cerebral artery and the superior cerebellar artery and through the internal segment of the peduncular crus, which is formed by frontopontine fibers located medial to the corticonuclear and corticospinal fibers. ${ }^{4,41} \mathrm{To}$ have a better exposure of the anterolateral surface of the midbrain and pons, some neurosurgeons use transpetrous approaches and their variations (Fig. 16B): retrolabyrinthine, with partial labyrinthectomy, or translabyrinthine. Nevertheless, these approaches add a greater risk of complications such as damage to the facial nerve, auditory deficits, and CSF leak. . $^{14,18,27,40}$

The standard approach to lesions on the lateral sur- face of the midbrain is the infratentorial supracerebellar approach, ${ }^{20,46,47}$ with its variations (median, paramedian, and far-lateral) (Fig. 16C), ${ }^{2,10}$ or a combined supra- and infratentorial approach. ${ }^{40}$ The main microsurgical landmark is the lateral mesencephalic sulcus. The incision of the sulcus exposes a surgical route limited anteriorly by the substantia nigra, posteriorly by the medial lemniscus, and medially by the red nucleus and by the roots of the oculomotor nerve. ${ }^{35}$

Lesions at the quadrigeminal plate can be reached by an infratentorial supracerebellar approach. The main anatomical landmarks are the colliculi, and the safe entry zone may be supra- or infracollicular (Fig. 16C and D). ${ }^{3}$

\section{Approaches to the Pons}

To approach the pons it is important to consider particularly the following structures, from anterior to posterior and from lateral to medial: the pyramidal tract; medial and lateral lemnisci; real and apparent origin of CNs V, VI, VII, and VIII; and the longitudinal medial fasciculus.

Lesions located at the anterolateral surface of the pons, cerebellopontine angle, and middle cerebellar peduncle can be reached through a retrosigmoid approach through a lateral suboccipital craniotomy (Fig. 16B and C). ${ }^{14,33,34,40,41}$ The main anatomical landmarks are the emergence of the trigeminal nerve and the CN VII-VIII complex, and the safe entry zone to this part of the brainstem is located between CNs V and VII.,41 The so-called peritrigeminal area has a triangular shape and is limited medially by the pyramidal tract, laterally by the emergence of $\mathrm{CN} \mathrm{V}$, and on the base by the pontomedullary sulcus (Fig. 12). ${ }^{35} \mathrm{Le}-$ sions extending into the anterolateral surface of the midbrain can be dealt through a transtentorial subtemporal approach $^{7,8}$ or through a presigmoid and transpetrous approach (Fig. 16A-C). 14,16,18,28

Lesions affecting the superior cerebellar peduncle, the tegmen of the pons, and the middle cerebellar peduncle can be managed through an infratentorial supracerebellar approach with a paramedian route to access the interpeduncular sulcus (situated between the superior and middle cerebellar peduncles). In such cases, the appropriate exposure requires also the removal of the quadrangular lobule of the tentorial surface of the cerebellar hemisphere (Fig. $16 \mathrm{~A}, \mathrm{~B}$, and D).

Lesions located on the posterior surface of the pons, and hence in contact with the floor of the fourth ventricle, are accessible through a median suboccipital craniotomy. The fourth ventricle can be reached through a telovelar ${ }^{28}$ or a transvermian approach, or through the cerebellomedullary fissure..$^{40,41}$ The main anatomical landmarks are the facial colliculus, the median sulcus, and the acoustic striae. The safe entry zones are the suprafacial triangle, the infrafacial triangle, and the median sulcus above the facial colliculus (Fig. 16C). 3,14,41

\section{Approaches to the Medulla Oblongata}

Lesions located on the anterolateral surface of the medulla oblongata can be better accessed through the farlateral approach, $, 7,45$ which requires a lateral suboccipital craniectomy with resection of the posterior arch of the atlas (C-1) and partial drilling of the posterior third of the 


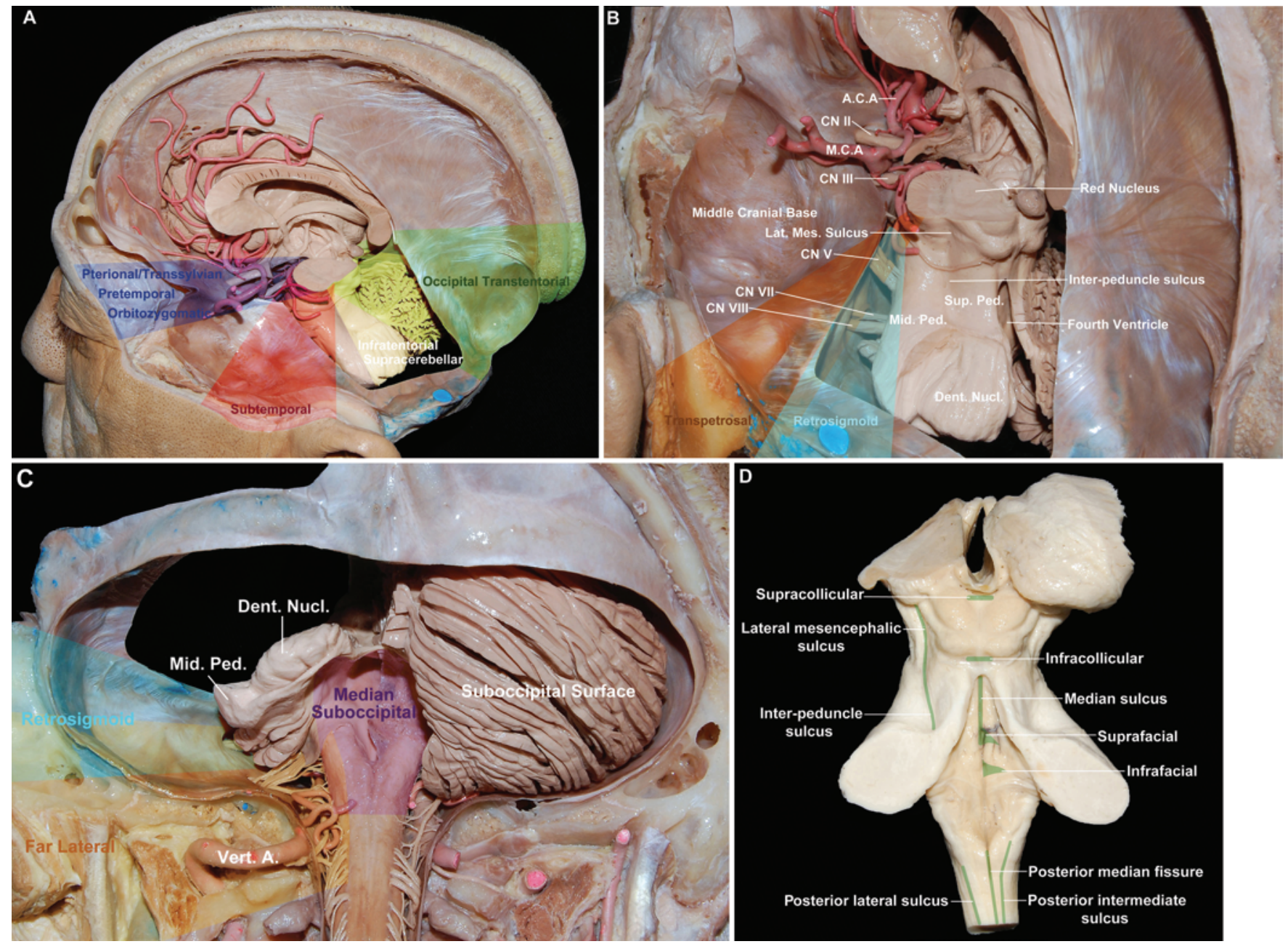

FIG. 16. A-C: Common surgical approaches to different areas of the brainstem. D: Posterior view of the brainstem showing safe entry zones. A.C.A = anterior cerebral artery; Dent. Nucl. = dentate nucleus; Lat. Mes. Sulcus = lateral mesial sulcus; M.C.A = middle cerebral artery; Mid. Ped. = middle cerebellar peduncle; Sup. Ped. = superior cerebellar peduncle; Vert. A. = vertebral artery. Figure is available in color online only.

occipital condyle (Fig. 16C). Different patient positions can be used for this approach, including park-bench, semisitting, and lateral decubitus. . $1,17,34,41,45^{\text {The main anatomi- }}$ cal landmarks are the medullary olive, emergence of the lower cranial nerves, and the first cervical spinal nerve. The retro-olivary sulcus represents a safe entry zone since the olive offers a surgical space of $13.5 \mathrm{~mm}$ craniocaudal, $7 \mathrm{~mm}$ transverse, and $2.5 \mathrm{~mm}$ anteroposterior. ${ }^{35}$ Another option is the anterolateral sulcus between $\mathrm{CN}$ XII and C-1 (Fig. 14C) ${ }^{5,14}$

The surgical approaches to the posterior surface of the medulla oblongata can be divided into superior or intraventricular, and inferior. The approach through the ventricle has a greater risk of neurological deficits, including dysphagia due to damage to the hypoglossal nucleus and cardiovascular dysfunction because of injury to the calamus scriptorius. ${ }^{14,41}$

The approach to the inferior portion is made through a median suboccipital craniotomy (Fig. 16C). The safe entry zones are the median posterior fissure below the obex, the posterior intermediate sulcus, and the posterolateral sulcus (Fig. 16D). ${ }^{14,41}$

All posterior fossa approaches at our institution are preferably performed with the patient in the semisitting position.

\section{Conclusions}

Despite advances in neuroimaging techniques and intraoperative electrophysiological monitoring, microsurgical training and deep knowledge of the external and internal morphology of the brainstem are fundamental when dealing with pathologies of this region. Severe neurological deficits and disability can be caused due to neurosurgical trauma.

When choosing the safest entry zone to the brainstem, it is important to have in mind that the best approach may not always be the shorter or the easier route for the surgeon. Thus, this article emphasizes more particularly the arrangement of the white and the gray matter of the midbrain, pons, and medulla oblongata, which will guide the 
neurosurgeon during the procedure to make it safer and more successful.

\section{References}

1. Abla AA, Lekovic GP, Turner JD, de Oliveira JG, Porter R, Spetzler RF: Advances in the treatment and outcome of brainstem cavernous malformation surgery: a single-center case series of 300 surgically treated patients. Neurosurgery 68:403-415, 2011

2. Ammirati M, Bernardo A, Musumeci A, Bricolo A: Comparison of different infratentorial-supracerebellar approaches to the posterior and middle incisural space: a cadaveric study. J Neurosurg 97:922-928, 2002

3. Bricolo A: Surgical management of intrinsic brain stem gliomas. Op Tech Neurosurg 3:137-154, 2000

4. Bricolo A, Turazzi S: Surgery for gliomas and other mass lesions of the brainstem. Adv Tech Stand Neurosurg 22:261341, 1995

5. Cantore G, Missori P, Santoro A: Cavernous angiomas of the brain stem. Intra-axial anatomical pitfalls and surgical strategies. Surg Neurol 52:84-94, 1999

6. Carpenter MB, Sutin J: Human Neuroanatomy, ed 8. Baltimore: Williams \& Wilkins, 1983

7. Drake CG: Bleeding aneurysms of the basilar artery. Direct surgical management in four cases. J Neurosurg 18:230_ 238, 1961

8. Drake CG, Peerless SJ, Hernesniemi JA: Surgery of Vertebrobasilar Aneurysms: London, Ontario Experience on 1767 Patients. Vienna: Springer-Verlag, 1996, pp 21-27

9. de Oliveira E, Rhoton AL Jr, Peace D: Microsurgical anatomy of the region of the foramen magnum. Surg Neurol 24:293-352, 1985

10. de Oliveira JG, Lekovic GP, Safavi-Abbasi S, Reis CV, Hanel RA, Porter RW, et al: Supracerebellar infratentorial approach to cavernous malformations of the brainstem: surgical variants and clinical experience with 45 patients. Neurosurgery 66:389-399, 2010

11. Fernández-Miranda JC, Rhoton AL Jr, Alvarez-Linera J, Kakizawa Y, Choi C, de Oliveira EP: Three-dimensional microsurgical and tractographic anatomy of the white matter of the human brain. Neurosurgery 62 (6 Suppl 3):989-1028, 2008

12. Fujitsu K, Kuwabara T: Zygomatic approach for lesions in the interpeduncular cistern. J Neurosurg 62:340-343, 1985

13. Furst M, Aharonson V, Levine RA, Fullerton BC, Tadmor R, Pratt $\mathrm{H}$, et al: Sound lateralization and interaural discrimination. Effects of brainstem infarcts and multiple sclerosis lesions. Hear Res 143:29-42, 2000

14. Giliberto G, Lanzino DJ, Diehn FE, Factor D, Flemming KD, Lanzino G: Brainstem cavernous malformations: anatomical, clinical, and surgical considerations. Neurosurg Focus 29(3):E9, 2010

15. Hakuba A, Liu S, Nishimura S: The orbitozygomatic infratemporal approach: a new surgical technique. Surg Neurol 26:271-276, 1986

16. Hauck EF, Barnett SL, White JA, Samson D: Symptomatic brainstem cavernomas. Neurosurgery 64:61-71, 2009

17. Heros RC: Lateral suboccipital approach for vertebral and vertebrobasilar artery lesions. J Neurosurg 64:559-562, 1986

18. Kawase T, Toya S: Anterior transpetrosal approach for basilar trunk aneurysms: Further experience, in Pasqualin A, Da Pian R (eds): New Trends in Management of Cerebrovascular Malformations. Vienna: Springer-Verlag, 1994, pp 255-260

19. Klingler J: [Development of the macroscopic preparation of the brain through the process of freezing.] Schweiz Arch Neurol Psychiatr 36:247-256, 1935 (Ger)
20. Krause F: Operative Freilengung der Vierhugel, nebst Beobachtungen uber Hirndruck und Dekompression. Zentralbl Chir 53:2812-2819, 1926

21. Ludwig E, Klingler J: Atlas Cerebri Humani. Basel: S. Karger, 1956

22. Machado A: Neuroanatomia Funcional, ed 2. São Paulo: Atheneu, 1993

23. Martinez JAG, de Oliveira E, Tedeschi H, Wen HT, Rhoton AL Jr: Microsurgical anatomy of the brain stem. Op Tech Neurosurg 3:80-86, 2000

24. Matsushima T, Fukui M, Inoue T, Natori Y, Baba T, Fujii K: Microsurgical and magnetic resonance imaging anatomy of the cerebello-medullary fissure and its application during fourth ventricle surgery. Neurosurgery 30:325-330, 1992

25. Matsushima T, Rhoton AL Jr, Lenkey C: Microsurgery of the fourth ventricle: Part 1. Microsurgical anatomy. Neurosurgery 11:631-667, 1982

26. Morota N, Deletis V, Epstein FJ, Kofler M, Abbott R, Lee M, et al: Brain stem mapping: neurophysiological localization of motor nuclei on the floor of the fourth ventricle. Neurosurgery 37:922-930, 1995

27. Miller CG, van Loveren HR, Keller JT, Pensak M, el-Kalliny M, Tew JM Jr: Transpetrosal approach: surgical anatomy and technique. Neurosurgery 33:461-469, 1993

28. Mussi AC, Rhoton AL Jr: Telovelar approach to the fourth ventricle: microsurgical anatomy. J Neurosurg 92:812-823, 2000

29. Naidich TP, Duvernoy HM, Delman BN, Sorensen AG, Kollias SS, Haacke EM: Duvernoy's Atlas of the Human Brain Stem and Cerebellum: High-Field MRI, Surface Anatomy, Internal Structure, Vascularization and 3D Sectional Anatomy. New York: Springer-Verlag, 2009, pp 5-245

30. Nieuwenhuys R, Voogd J, van Huijzen C: The Human Central Nervous System. Berlin: Springer, 2008, pp 190-245

31. Ono M, Ono M, Rhoton AL Jr, Barry M: Microsurgical anatomy of the region of the tentorial incisura. J Neurosurg 60:365-399, 1984

32. Párraga RG, Ribas GC, Andrade SE, de Oliveira E: Microsurgical anatomy of the posterior cerebral artery in threedimensional images. World Neurosurg 75:233-257, 2011

33. Porter RW, Detwiler PW, Spetzler RF: Surgical approaches to the brain stem. Op Tech Neurosurg 3:114-123, 2000

34. Quiñones-Hinojosa A, Chang EF, Lawton MT: The extended retrosigmoid approach: an alternative to radical cranial base approaches for posterior fossa lesions. Neurosurgery 58 (4 Suppl 2):ONS-208-ONS-214, 2006

35. Recalde RJ, Figueiredo EG, de Oliveira E: Microsurgical anatomy of the safe entry zones on the anterolateral brainstem related to surgical approaches to cavernous malformations. Neurosurgery 62 (3 Suppl 1):9-17, 2008

36. Rhoton AL Jr: Cranial Anatomy and Surgical Approaches. Schaumburg: Lippincott Williams \& Wilkins, 2003, pp 522-526

37. Riley HA: Atlas of the Basal Ganglia, Brain Stem and Spinal Cord Based on Myelin-Stained Material, ed 2. New York: Hafner, 1960

38. Rubino PA, Rhoton AL Jr, Tong X: Oliveira Ed: Three-dimensional relationships of the optic radiation. Neurosurgery 57:219-227, 2005

39. Sala F, Manganotti P, Tramontano V, Bricolo A, Gerosa M: Monitoring of motor pathways during brain stem surgery: what we have achieved and what we still miss? Neurophysiol Clin 37:399-406, 2007

40. Sekhar L, Fessler R: Atlas of Neurosurgical Techniques: Brain. Stuttgart: Thieme, 2006, Vol 1, pp 285-305

41. Sindou M: Practical Handbook of Neurosurgery. New York: Springer, 2009, Vol 2, pp 349-372

42. Seoane E, Tedeschi H, de Oliveira E, Wen HT, Rhoton AL Jr: The pretemporal transcavernous approach to the interpe- 
duncular and prepontine cisterns: microsurgical anatomy and technique application. Neurosurgery 46:891-899, 2000

43. Snell RS: Neuroanatomía Clínica, ed 4. Buenos Aires: Editorial Panamericana, 1999, pp 189-218

44. Sociedade Brasileira de Anatomia: Terminologia Anatômica. São Paulo: Manole, 2001

45. Spetzler RF, Graham TF: The far-lateral approach to the inferior clivus and the upper cervical region: technical note. BNI Q 6:35-38, 1990

46. Stein BM: The infratentorial supracerebellar approach to pineal lesions. J Neurosurg 35:197-202, 1971

47. Stein BM: Surgical approach to the pineal tumors, in Wilkins RH, Rengachary SS (eds): Neurosurgery Update I: Diagnosis, Operative Technique and Neuro-Oncology. New York: McGraw-Hill, 1990

48. Standring S (ed): Gray's Anatomy, ed 40. Philadelphia: Churchill-Livingstone, 2008

49. Testut L, Latarjet A: Tratado de Anatomía Humana, ed 9. Barcelona: Editorial Salvat, 1997

50. Türe U, Yaşargil MG, Friedman AH, Al-Mefty O: Fiber dissection technique: lateral aspect of the brain. Neurosurgery 47:417-427, 2000

51. Vesalius A: De Humani Corporis Fabrica. Basel: Johannes Oporinus, 1543

52. Williams PL, Warwick R (eds): Gray's Anatomy, ed 36. Philadelphia: Saunders, 1980

53. Yasargil MG: Microneurosurgery: Vol I. Stuttgart: Thieme, 1984

54. Yaşargil MG: Microneurosurgery: Vol II. Stuttgart: Thieme, 1984

55. Yaşargil MG: Microneurosurgery: Vol 4a. Stuttgart: Thieme, 1994
56. Yaşargil MG, Fox JL: The microsurgical approach to intracranial aneurysms. Surg Neurol 3:7-14, 1975

57. Zabramski JM, Kiriș T, Sankhla SK, Cabiol J, Spetzler RF: Orbitozygomatic craniotomy. Technical note. J Neurosurg 89:336-341, 1998

58. Zhang J, Lv X, Jiang C, Li Y, Wu Z: Superior cerebellar artery infarction in endovascular treatment for tentorial dural arteriovenous fistulas. Eur J Radiol 74:e33-e37, 2010

\section{Disclosure}

The authors report no conflict of interest concerning the materials or methods used in this study or the findings specified in this paper.

\section{Author Contributions}

Conception and design: de Oliveira, Párraga, Possatti, Alves, Ribas. Acquisition of data: Párraga, Possatti. Analysis and interpretation of data: de Oliveira, Párraga, Possatti, Alves, Ribas. Drafting the article: all authors. Critically revising the article: all authors. Reviewed submitted version of manuscript: all authors. Approved the final version of the manuscript on behalf of all authors: de Oliveira. Administrative/technical/material support: de Oliveira, Ribas. Study supervision: de Oliveira, Ribas, Türe.

\section{Correspondence}

Evandro de Oliveira, Instituto de Ciências Neurológicas, Praça Amadeu Amaral, 27, 5 andar, CEP 01327-010, São Paulo, Brazil. email: icne@uol.com.br. 